\title{
Selective laser sintering fabrication of nano-hydroxyapatite/poly- $\varepsilon$-caprolactone scaffolds for bone tissue engineering applications
}

This article was published in the following Dove Press journal:

International Journal of Nanomedicine

31 October 2013

Number of times this article has been viewed

Yan Xia ${ }^{1}, *$

Panyu Zhou',*

Xiaosong Cheng',*

Yang $\mathrm{Xie}^{1, *}$

Chong Liang ${ }^{2}$

Chao Li'

Shuogui $\mathrm{Xu}^{1,2}$

'Department of Orthopedics, Changhai Hospital, Second Military Medical University, Shanghai, People's Republic of China; ${ }^{2}$ Department of Neurosurgery, The 8I Hospital of People's Liberation Army of China, Nanjing, People's Republic of China

*These authors contributed equally to this work
Correspondence: Shuogui Xu

Department of Orthopedics, Changhai Hospital, Second Military Medical

University, Shanghai 200433,

People's Republic of China

Tel +86 2I 3II6 I687

Fax +86 21 55226616

Email shuogui_xu@163.com
Abstract: The regeneration of functional tissue in osseous defects is a formidable challenge in orthopedic surgery. In the present study, a novel biomimetic composite scaffold, here called nano-hydroxyapatite (HA)/poly- $\varepsilon$-caprolactone (PCL) was fabricated using a selective laser sintering technique. The macrostructure, morphology, and mechanical strength of the scaffolds were characterized. Scanning electronic microscopy (SEM) showed that the nano-HA/PCL scaffolds exhibited predesigned, well-ordered macropores and interconnected micropores. The scaffolds have a range of porosity from $78.54 \%$ to $70.31 \%$, and a corresponding compressive strength of 1.38 MPa to 3.17 MPa. Human bone marrow stromal cells were seeded onto the nano-HA/PCL or PCL scaffolds and cultured for 28 days in vitro. As indicated by the level of cell attachment and proliferation, the nano-HA/PCL showed excellent biocompatibility, comparable to that of PCL scaffolds. The hydrophilicity, mineralization, alkaline phosphatase activity, and Alizarin Red S staining indicated that the nano-HA/PCL scaffolds are more bioactive than the PCL scaffolds in vitro. Measurements of recombinant human bone morphogenetic protein-2 (rhBMP-2) release kinetics showed that after nano-HA was added, the material increased the rate of rhBMP-2 release. To investigate the in vivo biocompatibility and osteogenesis of the composite scaffolds, both nano-HA/PCL scaffolds and PCL scaffolds were implanted in rabbit femur defects for 3,6, and 9 weeks. The wounds were studied radiographically and histologically. The in vivo results showed that both nano-HA/PCL composite scaffolds and PCL scaffolds exhibited good biocompatibility. However, the nano-HA/PCL scaffolds enhanced the efficiency of new bone formation more than PCL scaffolds and fulfilled all the basic requirements of bone tissue engineering scaffolds. Thus, they show large potential for use in orthopedic and reconstructive surgery.

Keywords: osseous defects, orthopedic surgery, biomimetic composite scaffold, reconstructive surgery

\section{Introduction}

Bone grafting has become a common procedure. Among tissue transplantation procedures, it is second only to blood transfusions. It is widely used in orthopedics, dentistry, and craniofacial surgery. ${ }^{1}$ It is estimated that millions of patients require bone grafts every year worldwide. The most commonly used bone grafts and bonegraft substitutes are autografts, allografts, and alloplastic or synthetic bone grafts. ${ }^{2}$ Although autologous bone transplantation is still the gold standard in bone repair and allografts remain attractive alternatives to autografts, they suffer from many inherent problems including limited availability, side effects at the site of bone harvesting, and the risk of disease transmission from donor to recipient. These challenges have limited their clinical application. ${ }^{3,4}$ 
Three-dimensional (3D) scaffolds are a key requirement of scaffold-based bone tissue engineering because scaffolds can mimic the structure and function of the extracellular matrix and support cell adhesion, proliferation, differentiation, and tissue regeneration. ${ }^{5}$ The most effective scaffolds are biocompatible, bioresorbable, osteogenic, and mechanically strong, with well-interconnected pore structures and porosity, and are easy to use and cost-effective to produce. ${ }^{6}$ Conventional techniques of scaffold fabrication are largely limited to chemical engineering methods, such as solution casting, porogen gel casting, solvent casting, particulate leaching, injection molding, and electrospinning. However, these methods do not allow the researcher to accurately control pore shape, size, or spatial distribution. ${ }^{7-9}$ Some methods involve organic solvents that can remain in the scaffolds after transplant, resulting in inflammatory reactions and toxic side effects. ${ }^{10,11}$

Rapid prototyping (RP) has attracted a great deal of attention because it allows the user to precisely control and to construct complex geometrical scaffolds with intricate internal and external architectures. ${ }^{12-15}$ Selective laser sintering (SLS) is one type of RP technology. SLS requires powdered materials, radiant heaters, a $\mathrm{CO}_{2}$ laser, and a computer control system. First, the predesigned computer-aided design (CAD) files must be uploaded to the computer. Then, the 3D scaffolds can be built layer-by-layer in selected regions. Each layer of powder is fused to the layer immediately underneath it. In this way, highly complex scaffolds can be produced without the need for organic solvents. These scaffolds may have large surface areas and can even be built in the shape of the specific bone tissue defect in question. SLS technology has been studied by several research teams. ${ }^{16-19}$

Concurrently, nano-scale biomaterials have drawn the attention of the research community because of their desirable biological and biomechanical properties. ${ }^{20}$ Sub-nano-, nano-, and submicron materials all have different surface characteristics. They can be used to selectively trigger integrin receptors and promote the differentiation of bone marrow-derived mesenchymal stem cells into osteoblasts. Khang et al found that the roughness of the nano-submicron hybrid titanium surface can promote the differentiation of osteoblasts on sub-nano-, nano-submicron, and nanometer titanium surfaces. ${ }^{21}$

The current study of fabrication of nano-hydroxyapatite (HA)/poly- $\varepsilon$-caprolactone (PCL) scaffolds with the SLS technique focused on in vitro experiments and careful in vivo studies. Our goals were to fabricate nano-HA/PCL bone scaffolds using SLS and examine their physical characteristics, biocompatibility, and bioactivity using in vitro experiments, and to confirm their ability to promote bone defect healing in an animal model. To the best of our knowledge, this is the first study to apply nano-HA/PCL scaffold fabrication by the SLS technique for the repair of bone defects in vivo with important clinical implications for the treatment of bone disease.

\section{Materials and methods Materials}

\section{Nano-HA and PCL}

Nanoscale HA (Emperor, Nanjing, People's Republic of China) is a white powder with needle-like shapes under an electron microscope. The HA shapes were $150 \pm 20 \mathrm{~nm}$ long, $20 \pm 5 \mathrm{~nm}$ wide, and $\geq 99.5 \%$ pure. The PCL (Esun, Shenzhen, People's Republic of China) came as milk-white particles $3-5 \mathrm{~mm}$ in diameter with a molecular weight of 50,000 , melting point from $58^{\circ} \mathrm{C}-60^{\circ} \mathrm{C}$, a glass transition point of $-60^{\circ} \mathrm{C}$, a density of $1.08-1.12 \mathrm{~g} / \mathrm{cm}^{3}$, and a purity of $\geq 99.5 \%$. Both these materials were of medical grade.

\section{Fabrication of nano-HA/PCL biological composite material}

Because SLS can only build scaffolds using fine powders, the PCL particles had to be processed. However, general grinding and smashing techniques could not be used due to the extremely low melting point of PCL. Cryogenic freeze grinding was used instead. PCL particles were poured into a cryogenic freeze grinder (CM-420, Pudong Gaoqiao Testing Machinery Co., Ltd, Shanghai, People's Republic of China), and liquid nitrogen was continuously added during the grinding to prevent the temperature of PCL from rising to the glass transition point. The PCL particles became a powder during the high-speed impact and continuous grinding processes. Next, nano-HA and PCL were mixed at different weight ratios (with nano-HA weight accounting for $5 \%, 10 \%$, and $15 \%$, respectively). All mixtures had a total weight of $10 \mathrm{~kg}$. To ensure a thorough mixture, a V type powder mixer (VH-5, Xinchang Hongli Machinery Co., Ltd, Zhejiang, People's Republic of China) was used. The rotational speed was set at $30 \mathrm{rpm}$ and mixed for different lengths of time: 5 minutes, 10 minutes, 20 minutes, 30 minutes, 45 minutes, 1 hour, and 2 hours. The mixtures were then examined under a scanning electron microscope to determine the optimal time.

\section{Design and fabrication of scaffolds}

3D computer graphics software (Unigraphics NX 4.0; EDS, Plano, TX, USA) was used to design the CAD models of the scaffolds. In this study, long, cylindrical scaffolds 
were made. They were $6 \mathrm{~mm}$ in base diameter and $15 \mathrm{~mm}$ in height. The base and peripheral areas of the scaffolds had well-ordered pore structures about $1 \mathrm{~mm}$ in diameter. The prepared CAD models were prepared using Magics RP software (Magics 9.51; Caterpillar, Brussels, Belgium) and exported as stereolithography (STL) files, which were then imported into the SLS device.

The mixed nano-HA/PCL powder was then loaded into the SLS machine. Based on a previous study by Wiria et al, ${ }^{18}$ the SLS parameters were set as follows: diameter of laser beam $150 \mu \mathrm{m}$; internal scanning beam power $4.5 \mathrm{~W}$; peripheral scanning beam power $3 \mathrm{~W}$; support scanning beam power $3 \mathrm{~W}$; internal scan speed $1.25 \mathrm{~m} /$ second; peripheral scan speed $0.55 \mathrm{~m} /$ second; support scan speed $1.33 \mathrm{~m} /$ second; and layer thickness $150 \mu \mathrm{m}$. When the scaffold was complete, the growth chamber was cooled for 1 hour before the sample was removed. Excess powder remaining in the scaffold pore space was blown off. Using the same sintering method, four different types of scaffolds were made with different proportions of nano-HA to PCL by weight (ie, pure PCL, PCL with 5 $\mathrm{wt} \%$ nano-HA, PCL with $10 \mathrm{wt} \%$ nano-HA, and PCL with $15 \mathrm{wt} \%$ nano-HA).

\section{Physical characteristics of scaffolds Porosity}

The porosity of the scaffolds was determined using the Archimedes method and calculated using the following formula: ${ }^{22}$

$$
\text { Porosity }=(\mathrm{m} 2-\mathrm{m} 1) /(\mathrm{m} 2-\mathrm{m} 3) \times 100 \% \text {. }
$$

Here, $\mathrm{m} 1$ is the dry weight in air, $\mathrm{m} 2$ is the saturated wet weight in air, and $\mathrm{m} 3$ is the wet weight suspended in water. The porosities of the scaffolds ( $n=5$ of each type) were measured, and the average porosity was calculated for each type.

\section{Mechanical strength test}

Compression tests were performed on a universal material testing machine (Instron 5567; Instron, Norwood, MN, USA) equipped with a model 2519-104 force transducer at a crosshead speed of $0.5 \mathrm{~mm} /$ minute. The samples and testing parameters were prepared and set according to the ASTM standard designation D695-02a. ${ }^{23}$ Each scaffold was $10 \times 10 \times 10 \mathrm{~mm}$ in size. They were subjected to mechanical tests. The compressive strengths of five scaffolds of each type were tested and the average compressive strength was calculated for each type.

\section{Morphology and microstructure}

The morphology of each scaffold was observed using scanning electronic microscopy (SEM) (Quanta-250 FEG; FEI, Hillsboro, OR, USA) to evaluate micro- and macrostructure.

\section{Biocompatibility and bioactivity in vitro Cell culture}

Human bone marrow stromal cells (hMSCs) were donated to this project by the Shanghai Ninth People's Hospital (Shanghai, People's Republic of China). ${ }^{24}$ They were propagated in alpha-modified minimum essential medium supplemented with $10 \%(\mathrm{v} / \mathrm{v})$ fetal bovine serum. The cells were kept in a humidified incubator at $37^{\circ} \mathrm{C}$ and $5 \% \mathrm{CO}_{2}$, and the medium was replaced every 3 days. The adherent cells were allowed to reach approximately $80 \%$ confluence (7-9 days for the first passage), and cells from passages 2-5 were used.

\section{Cell seeding}

The scaffolds were cut to $5 \mathrm{~mm}$ in height for cell seeding. Then they were checked to ensure that they were free from contamination before seeding. Ethylene oxide fumigation was adopted for sterilization. The hMSCs were enzymatically lifted from culture dishes using trypsin/ethylenediaminetetraacetic acid $(0.25 \%$ and $0.53 \mathrm{mM}$, respectively) and centrifuged for 5 minutes at $1,000 \mathrm{rpm}$. The cells were resuspended in fresh culture medium and then respectively seeded on PCL, nano-HA/PCL, and the blank discs in 24 -well cell culture plates. A seeding density of $5 \times 10^{3}$ cells/ well was used for cell proliferation studies, while $2 \times 10^{4}$ cells/well was used for osteogenic differentiation assays. The cells were cultured for 21 days with medium changed every 2-3 days.

\section{Cell attachment}

The cell morphology was observed using SEM (Quanta-250 FEG; FEI). The scaffold was removed from the plate 12 hours after cell seeding. Then the constructs were fixed for 24 hours with $2.5 \%$ glutaraldehyde ( $\mathrm{pH} 7.4$ ) and then for 4 hours in $1 \%$ osmium tetroxide. The constructs were dehydrated in a graded series of ethanol for 10 minutes, critically point dried, and sputtered with gold.

\section{Cell proliferation assay}

Cells cultivated in otherwise identical wells containing no scaffolds served as controls. Plates were incubated in Dulbecco's Modified Eagle's Medium/Nutrient Mixture F-12 medium 
(Sigma-Aldrich, St Louis, MO, USA) containing 10\% fetal bovine serum at $37^{\circ} \mathrm{C}$ in a $5 \% \mathrm{CO}_{2}$ incubator for 1,4 , and 7 days. Cell viability was studied using the CCK-8 (CK04, Dojindo, Kumamoto, Japan) assays. As a control, we monitored cell growth in the absence of any supporting scaffold. Briefly, $450 \mu \mathrm{L}$ of serum-free culture medium and $50 \mu \mathrm{L}$ CCK-8 solution were added to each sample. The samples were allowed to incubate at $37^{\circ} \mathrm{C}$ for 3 hours. Then, optical density was measured at $450 \mathrm{~nm}$ using a plate spectrophotometer (MK3; Thermo Fisher Scientific, Waltham, MA, USA). Five parallel replicates were performed for each sample.

\section{Hydrophilicity}

The sessile drop method was used to evaluate the water contact angles and therefore the hydrophilicity of all porous scaffolds (JC 2000D3, Powereach CO., Ltd, Shanghai, People's Republic of China).

\section{Immersion of scaffolds in simulated body fluid (SBF)} $\mathrm{SBF}$ was prepared from $\mathrm{NaCl}, \mathrm{NaHCO}_{3}, \mathrm{KCl}, \mathrm{K}_{2} \mathrm{HPO}_{4} \cdot 3 \mathrm{H} 2 \mathrm{O}$, $\mathrm{MgCl}_{2} \cdot 6 \mathrm{H}_{2} \mathrm{O}, \mathrm{CaCl}_{2} \cdot 2 \mathrm{H}_{2} \mathrm{O}$, and $\mathrm{Na}_{2} \mathrm{SO}_{4}$ in ion-exchanged and distilled water. This fluid was buffered with tris (hydroxymethyl-aminomethane, $\mathrm{NH}_{2} \mathrm{C}\left[\mathrm{CH}_{2} \mathrm{OH}\right]_{3}$ ) and hydrochloric acid $(\mathrm{HCl})$ to $\mathrm{pH} 7.4$ at $37^{\circ} \mathrm{C} .{ }^{18}$ The final concentration $(\mathrm{mM})$ of the different ionic species in the SBF was: $\mathrm{Na}^{+}$142.0, $\mathrm{K}^{+}$5.0, $\mathrm{Mg}^{2+} 1.5, \mathrm{Ca}^{2+}$ 2.5, $\mathrm{Cl}^{-}$148.2, $\mathrm{HCO}_{3}^{-}$4.2, $\mathrm{HPO}_{4}{ }^{2-} 41.0$, and $\mathrm{SO}_{4}{ }^{2-} 40.5$. The specimens were placed in six-well plates and then immersed in SBF for 28 days in an incubator at $37^{\circ} \mathrm{C}$. The SBF solution was changed every 3-4 days, and a sample was removed after 7 days. The samples were dried at room temperature and then characterized using SEM and X-ray energy dispersive spectroscopy to determine their ability to form apatite.

\section{Alkaline phosphatase (ALP) activity and Alizarin Red S staining}

The level of hMSC mineralization was assessed using ALP and Alizarin Red S staining. The hMSCs were cultured with pure PCL and nano-HA/PCL scaffolds for 7, 14, and 21 days. On days 7 and 14, ALP staining was performed in accordance with the kit manufacturer's instructions (Sigma-Aldrich). The hMSCs were washed three times with phosphate buffered solution (PBS) and fixed in 4\% paraformaldehyde for 15 minutes. The cells were then incubated with naphthol ASBI phosphate for 20 minutes. After immersion in acetic acid for 1 minute, cells were washed using double-distilled (DD) water, placed on cover slips, and treated with glycogelatin. The cells were viewed with a light microscope to assess staining. On day 21 , the hMSCs were also washed three times with PBS, fixed in 95\% ethanol for 10 minutes, washed twice with DD water, and stained with Alizarin Red solution $(2 \%, \mathrm{pH} 4.2)$ for 30 minutes at $37^{\circ} \mathrm{C}$. They were then rewashed several times with DD water to remove excess stain and observed with light microscopy.

\section{Release kinetics of recombinant human bone morphogenetic protein-2 (rhBMP-2)}

The scaffolds were placed in $5 \mathrm{~mL}$ of rhBMP-2 at $100 \mu \mathrm{g} / \mathrm{mL}$ for 360 hours with gentle shaking at ambient temperature. This allowed the scaffold to absorb rhBMP-2. Three rounds of washing with PBS and drying followed. To calculate the loading efficiency of rhBMP-2, we subtracted the rhBMP-2 remaining in solution from that in the control PBS experiment treated identically. To study growth factor release, the rhBMP-2-treated scaffolds were placed in PBS (2 mL) supplemented with $1 \%$ bovine serum albumin (SigmaAldrich). The material was incubated at $37^{\circ} \mathrm{C}$ for 3 days with gentle agitation $(50 \mathrm{rpm})$. The media were serially collected, replaced with saline, and assayed for rhBMP-2 with enzymelinked immunosorbent assay as per the manufacturer's instructions. The pretreatment groups were similarly studied. After the scaffold adsorbed rhBMP-2, we washed the scaffold three times with PBS and the scaffold dried at room temperature. Then, the hMSCs were added for 4, 7, and 14 days of growth. ALP was measured with the technique of Lowry et $\mathrm{al}^{25}$ and Lieberherr et al. ${ }^{26}$

\section{Biocompatibility and osteogenesis in vivo Surgical procedures}

This study was performed in accordance with National Institutes of Health (NIH) guidelines for the care and use of laboratory animals and approved by the Research Center for Laboratory Animals of Shanghai University of Traditional Chinese Medicine, Shanghai, People's Republic of China. A total of 27 healthy adult New Zealand White rabbits (weight: $2.8-3.2 \mathrm{~kg}$ ) were studied. The lateral epicondyle of the femur was chosen as the site of bone defect. All rabbits were divided into three groups: A, B, and C. The rabbits in group A were given scaffolds made of PCL with $15 \mathrm{wt} \% \mathrm{HA}$; the rabbits in group B were given scaffolds made of pure PCL; and group $\mathrm{C}$ was a blank control. The rabbits were individually caged and allowed to acclimate for over 1 month. The surgical sites were shaved, disinfected, and covered with sterile drapes. Pentobarbital sodium $(0.1 \mathrm{~mL} / 100 \mathrm{~g}$ body weight [SigmaAldrich]) was used as a general anesthetic, and xylocaine was used as a local anesthetic. A $2 \mathrm{~cm}$ oblique incision was 
made at the area of the lateral epicondyle of the femur. The fascia muscles were separated, exposing the lateral epicondyle. A $2 \mathrm{~mm}$ drill bit was used to create a hole in the lateral epicondyle. Each hole was gradually widened and deepened with drills of increasing size until it was $6 \mathrm{~mm}$ in diameter and $10 \mathrm{~mm}$ deep. To match the size of the bone defect, we cut the cylindrical scaffolds to a height of $10 \mathrm{~mm}$ and a bottom diameter of $5 \mathrm{~mm}$. The two groups of scaffolds were carefully implanted into the wound. After surgical closure, rabbits were given penicillin-streptomycin (Roche, Basel, Switzerland) through intramuscular injection at a dosage of 400,000 IU per day for 3 days to reduce the risk of postoperative infection. The rabbits were sacrificed at 3,6, and 9 weeks after surgery for radiological and histological examinations with $\mathrm{n}=3$ at each time point.

\section{In vivo 3D X-ray micro-computed tomography (CT) imaging}

Real-time live imaging of the rabbit femoral defects was performed using X-ray micro-CT (SMX-100CT-SV3 Type; Shimadzu Ltd, Tokyo, Japan) (n=3) 3, 6, and 9 weeks postsurgery. Femur samples were scanned across $360^{\circ}$ at $0.49^{\circ}$ increments and a spatial resolution of $35 \mathrm{~mm}$. Images were recorded, digitized, and reconstructed using a modified Feldkamp cone beam tomographic reconstruction algorithm. They were then uploaded to the 3D modeling software, VGStudio (Volume Graphics GmbH, Heidelberg, Germany) to stack the 2D image tiles into a 3D model.

\section{Histological analysis}

After imaging, the samples were fixed in 10\% neutral buffered formalin solution for 3 days. They were then dehydrated through alcohol gradients of $70 \%, 90 \%$, and $100 \%$ ethanol and embedded in polymethylmethacrylate. Then the samples were continuously cut perpendicular to the longitudinal axis of the femur with a Leica SP1600 saw microtome (Leica Microsystems, Wetzlar, Germany) with a slice thickness of 150-200 $\mu \mathrm{m}$. The slices were then ground and polished to a thickness of $50 \pm 10 \mu \mathrm{m}$. They were stained with Van Gieson's method and observed under an optical microscope (Leica Microsystems). Three continuous slices including the center of the bone grafting site were examined for bone growth into the scaffold and biodegradation of the material.

\section{Statistical analysis}

All quantitative data are here expressed as the mean \pm standard deviation. They were analyzed with SPSS statistical software (v 11.0; IBM Corporation, Armonk, NY, USA).
Statistical comparisons were made using analysis of variance (ANOVA). Statistical significance was considered to be greater than $95 \%$ confidence level $(P<0.05)$.

\section{Results Evaluation of the scaffold Scaffold morphology}

The CAD models of the scaffolds and the sintered scaffolds are shown in Figure 1. The scaffolds were cylindrical in shape, $15 \mathrm{~mm}$ in height, and $5 \mathrm{~mm}$ in diameter at the base.

The SEM images of the surface morphology and microstructure of the fabricated porous scaffolds are shown in Figure 2. The main body of the nano-HA/PCL scaffold contains micron-scale PCL particles. As shown in Figure 2A and $\mathrm{B}$, the base and the peripheral area of the scaffold showed well-ordered and interconnected macropores. The scaffolds' pore sizes ranged from $600 \mu \mathrm{m}$ to $800 \mu \mathrm{m}$. Micropores were seen among the PCL particles. These micropores were very tiny and not well ordered, with pore sizes ranging from several to dozens of microns in diameter (Figure 2C). At higher magnification $(\times 5,000$ [Figure 2D]) it is clear that the PCL particles were evenly attached to the nanoscale HA particles.

\section{Porosity and mechanical properties of scaffolds}

The porosity and compressive strength of each sample are given in Table 1. When the other processing parameters were fixed and the amount of nano-HA increased from $0 \mathrm{wt} \%$ to $15 \mathrm{wt} \%$, the porosity of the scaffolds decreased from about $78.54 \% \pm 2.98 \%$ to $70.31 \% \pm 1.47 \%(P<0.05)$, but the compressive strength of the scaffolds increased from $1.38 \pm 0.16 \mathrm{MPa}$ to $3.17 \pm 0.11 \mathrm{MPa}(P<0.05)$. All the composite scaffolds were used in cell culture, but only the PCL scaffold with $15 \mathrm{wt} \%$ nano-HA was implanted into the rabbits.

\section{Biocompatibility and bioactivity in vitro Cell attachment and proliferation}

The morphology of the hMSCs attached to the PCL and nano-HA/PCL scaffolds was evaluated using SEM. Micrographs taken after 12 hours of culture were considered representative of hMSC attachment and spreading. Cells were tightly anchored to the surfaces of all scaffolds. Cells exhibited fibroblast-like morphology, indicating that the cells had finished attaching and had begun to spread (Figure 3).

Cell proliferation was analyzed using a CCK-8 assay (Figure 4). Cell proliferation is expressed as the percentage of viable cells exposed to the scaffolds. Cell proliferation of the control cells on days 1,4 , and 7 was always considered 
A
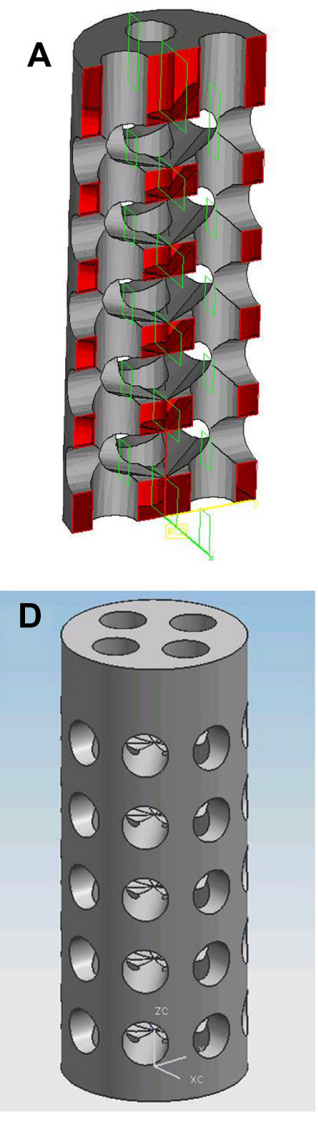

B
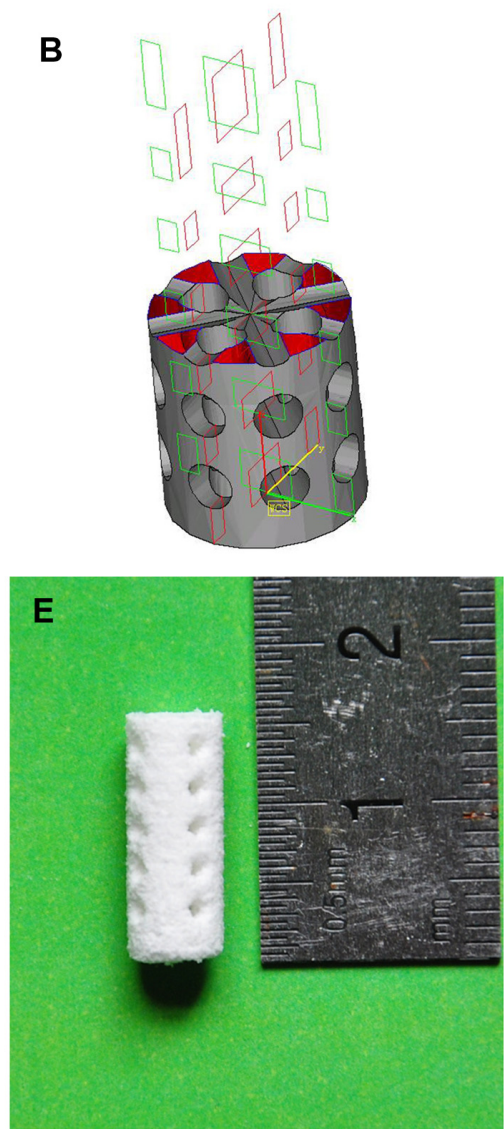

C
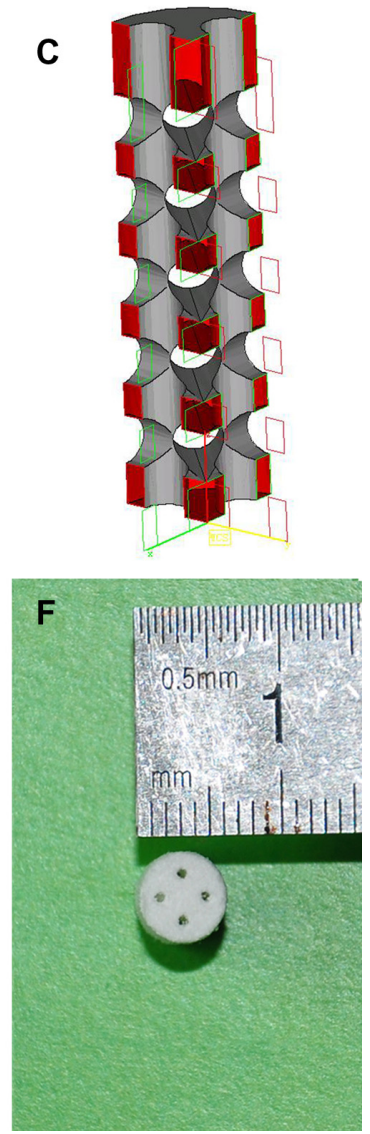

Figure I Computer-aided design models.

Notes: (A-D) scaffolds; (E and F) sintered scaffolds.

to be $100 \%$. On day 1 , cell proliferation on scaffolds made with 0 (pure PCL), 5,10 , and $15 \mathrm{wt} \%$ nano-HA was $99.7 \% \pm 3.83 \%$, $103.41 \% \pm 4.15 \%, 107.15 \% \pm 4.23 \%$, and $109.48 \% \pm 4.68 \%$, respectively. The increase in cell proliferation relative to the control was significant $(P<0.05)$ for the scaffolds at 10 and $15 \mathrm{wt} \%$ nano-HA. The increase in cell proliferation relative to the pure PCL was also significant $(P<0.05)$ for the scaffolds at 10 and $15 \mathrm{wt} \%$ nano-HA. Cell proliferation values on day 4 were $101.61 \% \pm 4.36 \%, 107.23 \% \pm 4.57 \%, 109.76 \% \pm 4.34 \%$, and $113.83 \% \pm 4.57 \%$ for scaffolds containing $0,5,10$, and 15 $\mathrm{wt} \%$ nano-HA, respectively. The increase relative to the control was significant $(P<0.05)$ for the scaffolds at 5, 10, and $15 \mathrm{wt} \%$ nano-HA, and the cell proliferation of the scaffolds compared to the pure PCL was significant $(P<0.05)$ for the scaffolds at 10 and $15 \mathrm{wt} \%$ nano-HA. The cell proliferation values on day 7 for the scaffolds at $0,5,10$, and $15 \mathrm{wt} \%$ nano-HA were $105.94 \% \pm 4.95 \%, 112.31 \% \pm 4.94 \%, 113.24 \% \pm 5.33 \%$, and $117.62 \% \pm 4.83 \%$, respectively. This increase relative to the control was significant $(P<0.05)$ for scaffolds at 5,10 , and $15 \mathrm{wt} \%$ nano-HA, and the cell proliferation of the scaffolds relative to pure PCL was also significant $(P<0.05)$ for the scaffolds made with $15 \mathrm{wt} \%$ nano-HA only. The CCK-8 assay clearly implies that the scaffolds made of nano-HA and PCL - in particular those made with $15 \mathrm{wt} \%$ nano-HA - provided an excellent microenvironment for hMSC growth. We also cultured $\mathrm{HaCaT}$ cells with the scaffold for 7 days, and the SEM showed that, after 7 days, $\mathrm{HaCaT}$ cells had grown into the scaffold (Figure S1).

\section{Hydrophilicity}

Previous studies have shown that the scaffold surface hydrophilicity has a profound influence on the bio-performance of biomaterials. Improved surface hydrophilicity can promote interactions between the polymer matrix and the cells, fostering cellular adhesion and growth. ${ }^{27}$ In this study, we evaluated the relative hydrophilicity of both PCL and the composite scaffolds by measuring their water contact angles using a sessile drop method (contact angle system OCA15; Data Physics USA, San Jose, CA, USA). The results are shown in Figure 5. It is clear that water contact angles fall sharply from $112.98^{\circ}$ for pure PCL to $87.42^{\circ}$ for PCL made of $5 \mathrm{wt} \%$ nano-HA. Values are $81.00^{\circ}$ for PCL made with $10 \mathrm{wt} \%$ nano-HA and $79.50^{\circ}$ for PCL made with $15 \mathrm{wt} \%$ nano-HA scaffolds. 


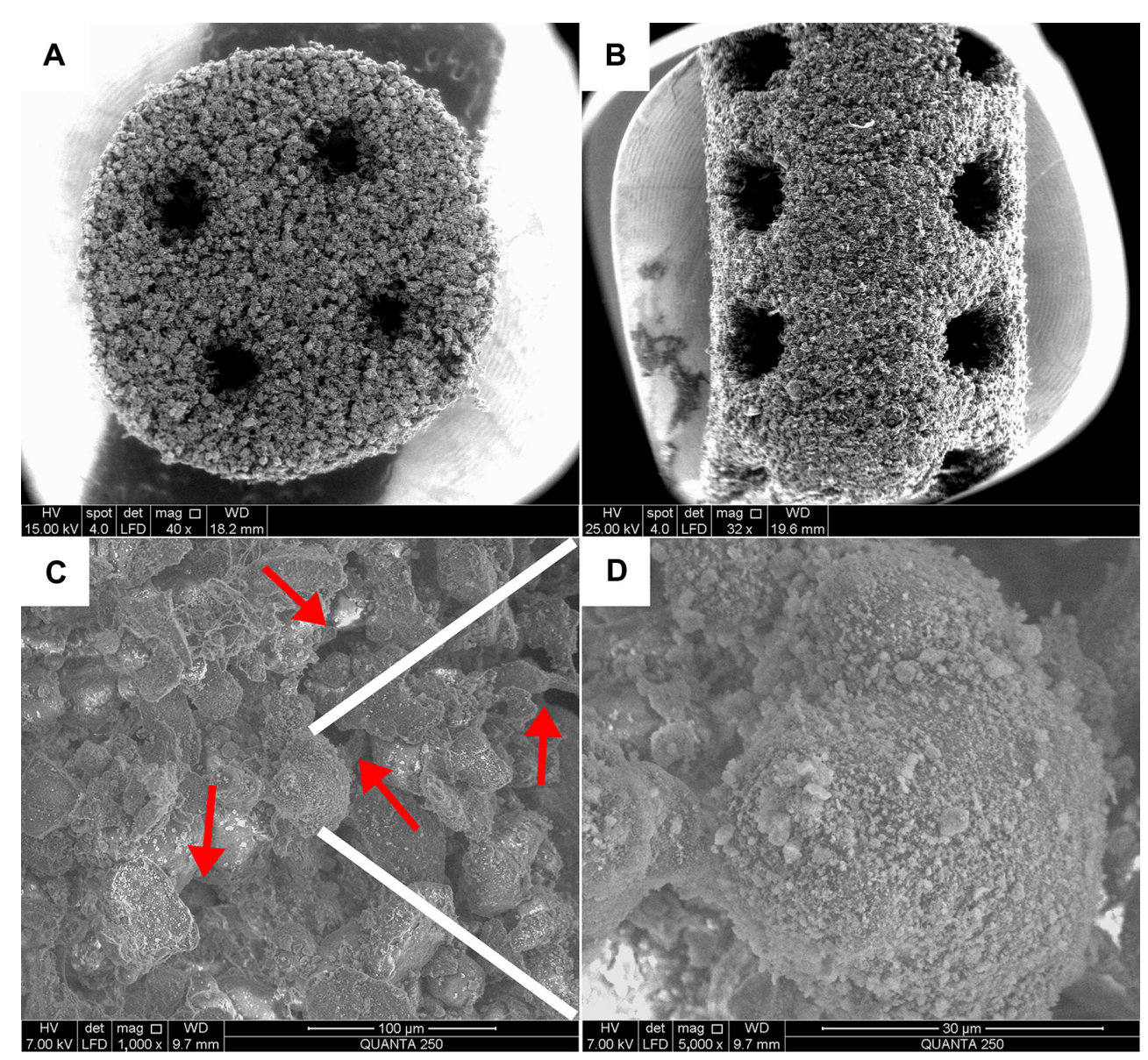

Figure 2 Scanning electronic microscopy micrographs of the scaffolds.

Notes: $(\mathbf{A})$ Base $(\times 40)$ and $(\mathbf{B})$ peripheral $(\times 32)$ areas of the nano-hydroxyapatite/poly- $\varepsilon$-caprolactone $(\mathrm{PCL})$ scaffolds with well-ordered and interconnected macropores from $600 \mu \mathrm{m}$ to $800 \mu \mathrm{m}$. (C) Microstructure of the scaffolds $(\times I, 000)$. The micropores (red arrows) appeared among PCL particles with pore sizes of several microns in diameter. (D) The PCL particles were evenly attached to the nanoscale hydroxyapatite particles $(\times 5,000)$.

This demonstrates that adhesion of the nano-HA enhances the surface hydrophilicity of the PCL scaffolds. Increases in the proportion of nano-HA weights were associated with increases in the surface hydrophilicity of the scaffolds.

\section{Bioactivity analysis using SBF}

We noted that when the specimens were put into the SBF solution at 3 days, the pure PCL samples floated but the specimens containing HA remained submersed. This is because PCL is hydrophobic but HA is hydrophilic, thus water can-

Table I Porosity and compressive strength of the scaffolds $(n=5)$

\begin{tabular}{lll}
\hline Specimen type & $\begin{array}{l}\text { Porosity } \\
\text { (\%) }\end{array}$ & $\begin{array}{l}\text { Compressive } \\
\text { strength (MPa) }\end{array}$ \\
\hline Pure PCL & $78.54 \pm 2.98$ & $1.38 \pm 0.16$ \\
PCL with 5 wt\% nano-HA & $75.32 \pm 1.74$ & $2.02 \pm 0.12$ \\
PCL with 10 wt\% nano-HA & $72.06 \pm 1.26$ & $2.67 \pm 0.20$ \\
PCL with I5 wt\% nano-HA & $70.31 \pm 1.47$ & $3.17 \pm 0.11$ \\
\hline
\end{tabular}

Note: Data are presented as mean \pm standard deviation.

Abbreviations: $\mathrm{HA}$, hydroxyapatite; $\mathrm{PCL}$, poly- $\varepsilon$-caprolactone. not easily enter the open pores of the pure PCL scaffolds. Micrographs of the PCL and nano-HA/PCL immersed in SBF for more than 7 days are shown in Figure 6. No obvious changes in the surface areas of the PCL samples were observed. This indicated that pure PCL was inactive in the SBF and that no HA had formed. In contrast, an apatite layer formed in the nano-HA/PCL scaffolds as indicated by a layer of white crystals upon immersion in SBF. These crystals are HA, a component normally found when $\mathrm{HA}$ interacts with $\mathrm{SBF}^{28}$

Energy dispersive spectroscopy analysis determined the calcium content of the scaffolds before and after immersion in SBF (Figure 7). The calcium contents of the scaffolds made with 0 (pure PCL), 5, 10, and $15 \mathrm{wt} \%$ nano-HA were $0,4.79 \% \pm 0.51 \%, 9.76 \% \pm 0.84 \%$, and $13.47 \% \pm 1.59 \%$, respectively, before the scaffolds were immersed in SBF. They were $1.30 \% \pm 0.34 \%, 14.78 \% \pm 1.14 \%, 30.47 \% \pm 2.61 \%$, and $38.18 \% \pm 2.66 \%$ after 3 days of immersion. As shown in Figure 7, the calcium content of the pure PCL scaffolds were relatively stable, but the calcium content of other scaffolds 

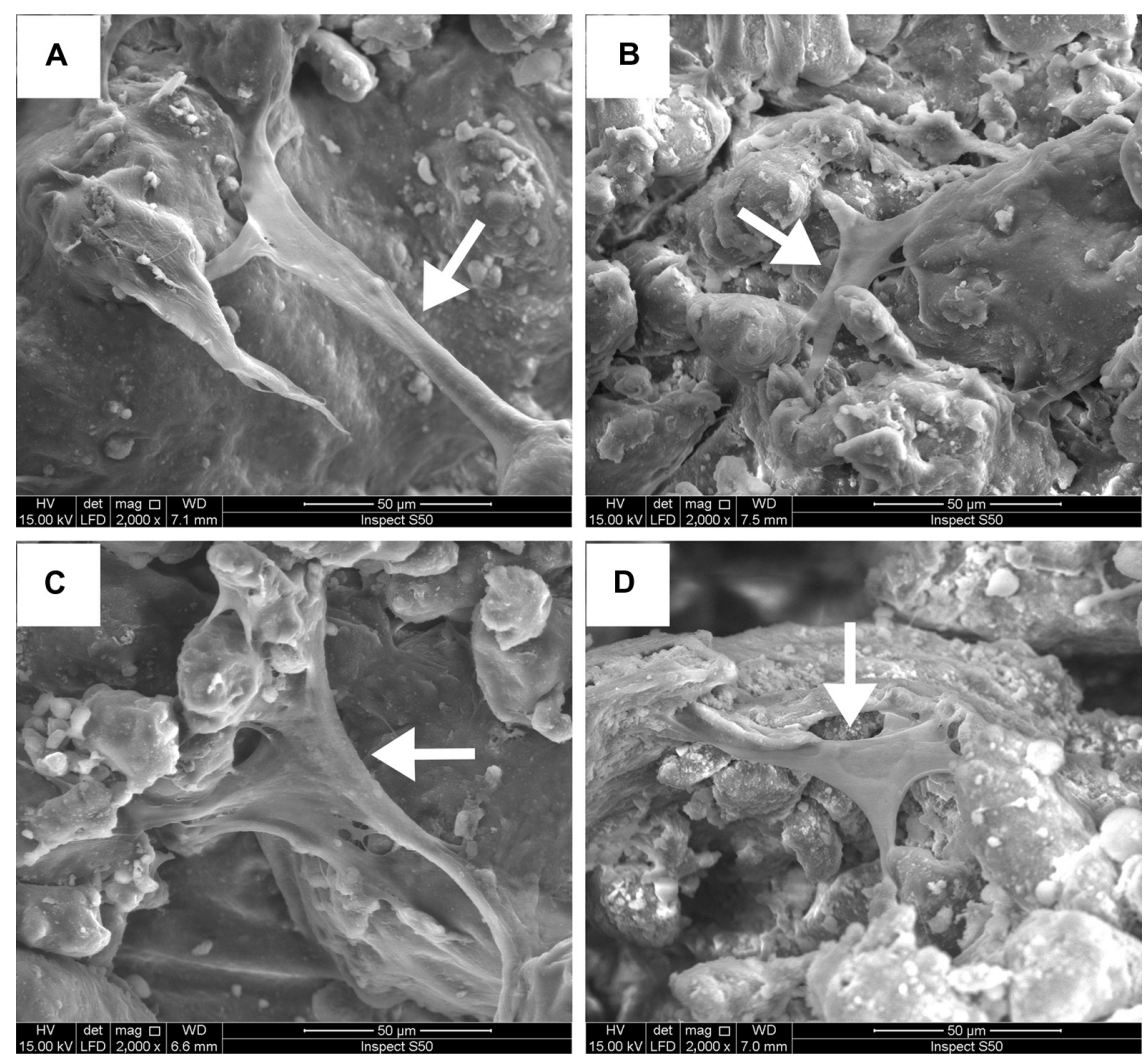

Figure 3 Scanning electronic microscopy photographs of the human bone marrow stromal cells (hMSCs).

Notes: hMSCs seeded on (A) pure poly- $\varepsilon$-caprolactone and poly- $\varepsilon$-caprolactone with (B) 5 wt\%, (C) 10 wt\%, and (D) 15 wt\% nano-hydroxyapatite scaffolds at 12 hours. Cells were found to be tightly anchored to the surfaces of all scaffolds and exhibited fibroblast-like morphology. White arrows: hMSCs.

increased significantly $(P<0.05)$. The higher the relative amount of nano-HA, the greater the increase.

\section{ALP and Alizarin Red S staining}

The differentiation of hMSCs into osteoblasts was demonstrated by the positive staining of ALP and Alizarin Red S staining (Figures 8 and 9).

\section{ALP staining}

The results of ALP staining after incubation of hMSC/scaffold constructs in common medium for 1 and 2 weeks are shown in Figure 8. The PCL scaffolds showed no significant difference in ALP staining between 1 and 2 weeks after staining, but obvious positive staining of ALP was observed in the nano-HA/PCL scaffolds. The most obvious positive staining

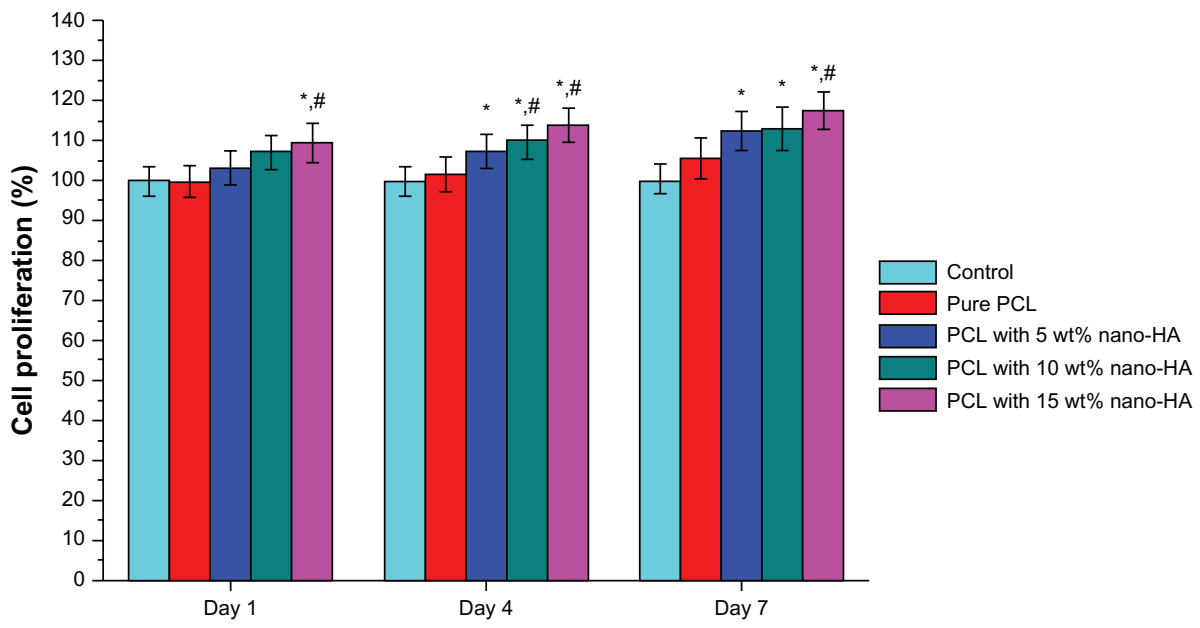

Figure 4 Cell viability of the extracts of the scaffolds at different nano-HA contents.

Notes: $* P<0.05$ versus control; ${ }^{*} P<0.05$ versus pure $P C L$ scaffolds.

Abbreviations: $\mathrm{HA}$, hydroxyapatite; $\mathrm{PCL}$, poly- $\varepsilon$-caprolactone. 

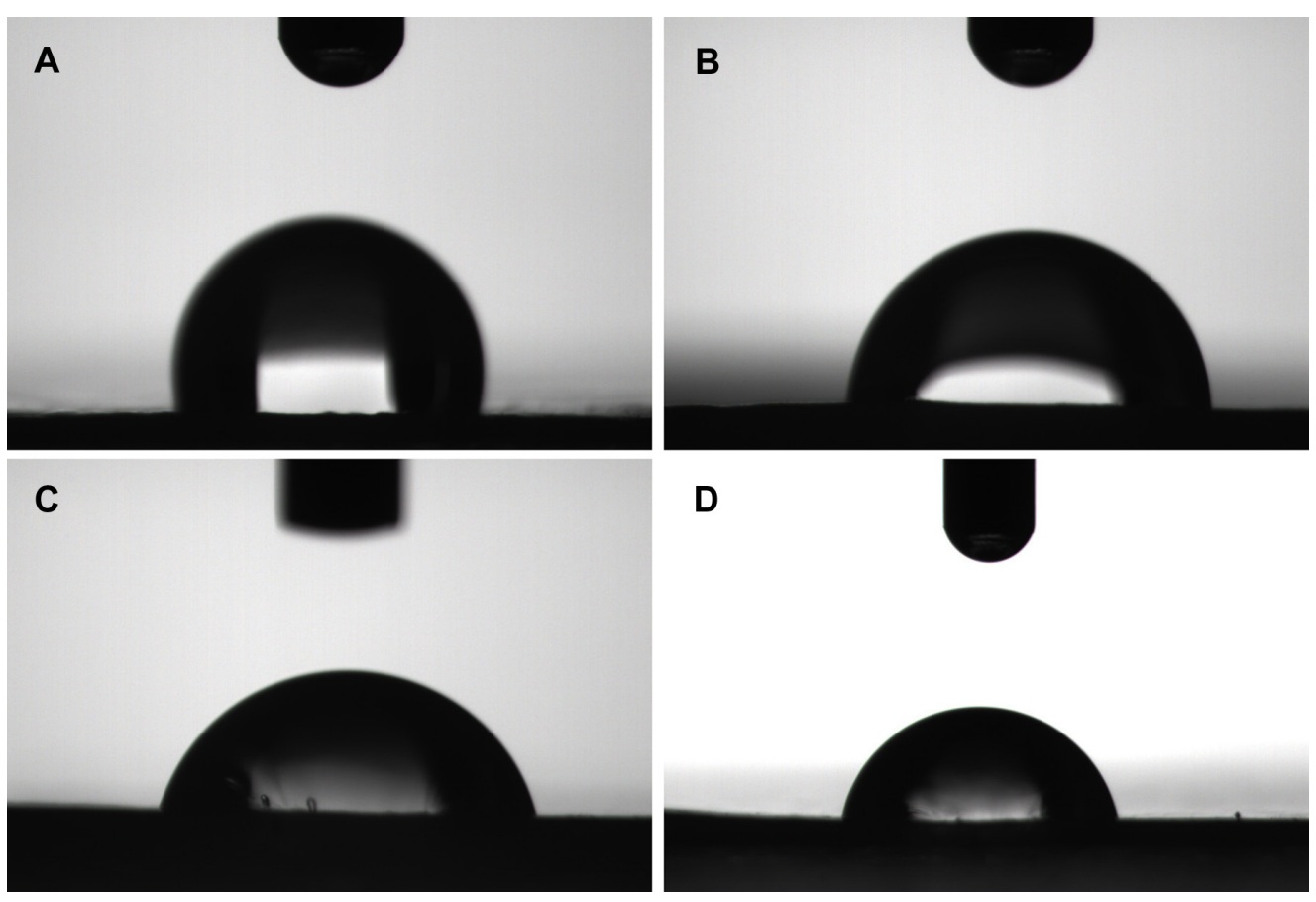

Figure 5 Water contact angles.

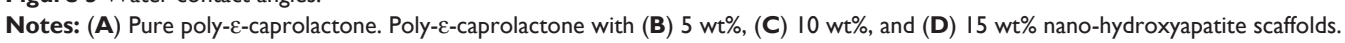
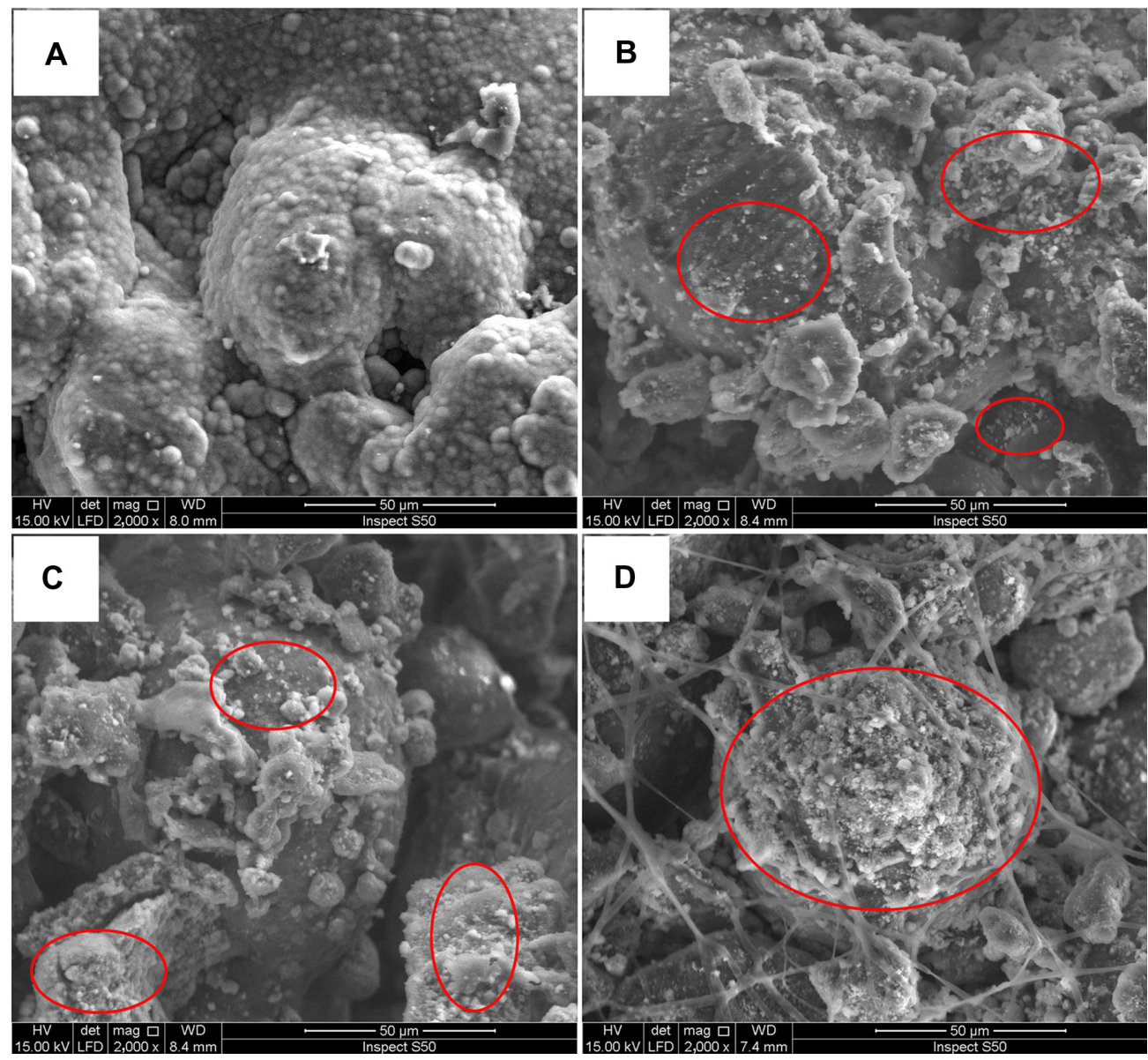

Figure 6 Scanning electronic microscopy photographs of scaffold surfaces.

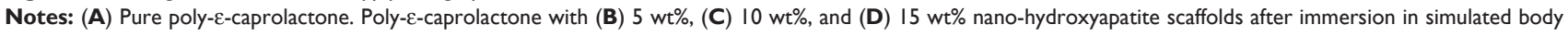
fluid at 3 days. Red circles: hydroxy-carbonate apatite formation. 


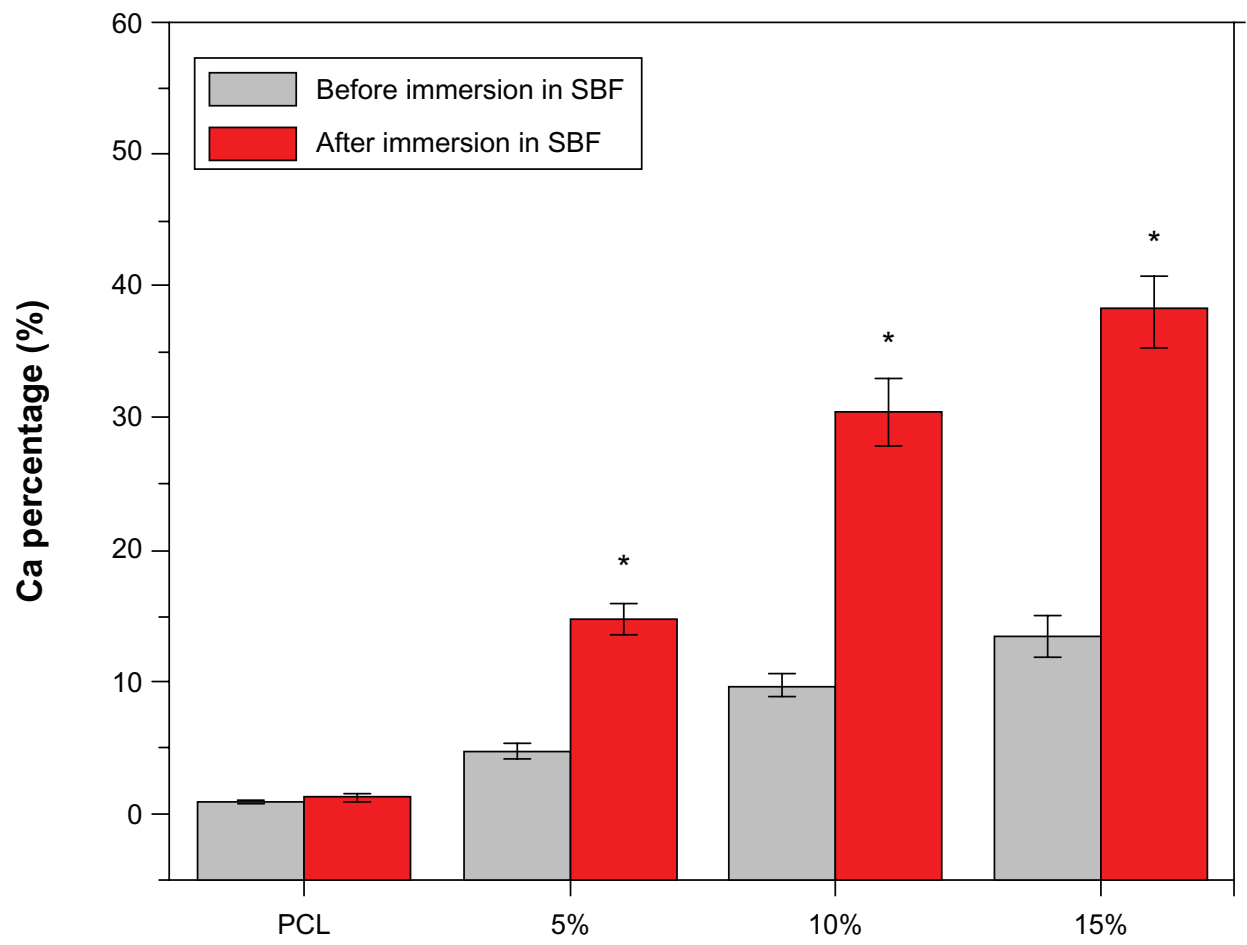

Figure 7 The \%Ca of the scaffolds with 0 (pure PCL), 5, 10, and 15 wt\% nano-hydroxyapatite before and after immersion in SBF. Notes: Data represent the mean $\pm S D(n=5)$. $* P<0.05$ versus before.

Abbreviations: $\mathrm{PCL}$, poly- $\varepsilon$-caprolactone; SBF, simulated body fluid; SD, standard deviation.

of ALP was shown in the $15 \mathrm{wt} \%$ nano-HA group and suggests that the nano-HA/PCL scaffolds promote the differentiation of hMSCs into osteoblasts. This effect increased as a function of the nano-HA weight proportion in the scaffold.

\section{Alizarin Red S staining}

As shown in Figure 9, after the hMSC/scaffold constructs were incubated in common medium for 21 days, more obvious Alizarin Red S staining was observed on the nano-HA/ PCL scaffolds (Figure 9B-D) than on pure PCL scaffolds (Figure 9A). The nano-HA/PCL scaffolds made with
$15 \mathrm{wt} \%$ nano-HA showed the most obvious positive staining. This indicates that the nano-HA/PCL scaffolds facilitate much more hMSC mineralization than PCL scaffolds.

\section{Release kinetics of rhBMP-2}

Figure 10 presents the rhBMP-2 release curves within 15 days in four groups of scaffolds. The rhBMP-2 release in the pure PCL scaffold group was fast. After 180 hours, $90 \%$ of the adsorbed rhBMP-2 was released; at 240 hours, rhBMP-2 release was nearly complete. In contrast, rhBMP-2 release was much slower and more consistent in nano-HA scaffolds.

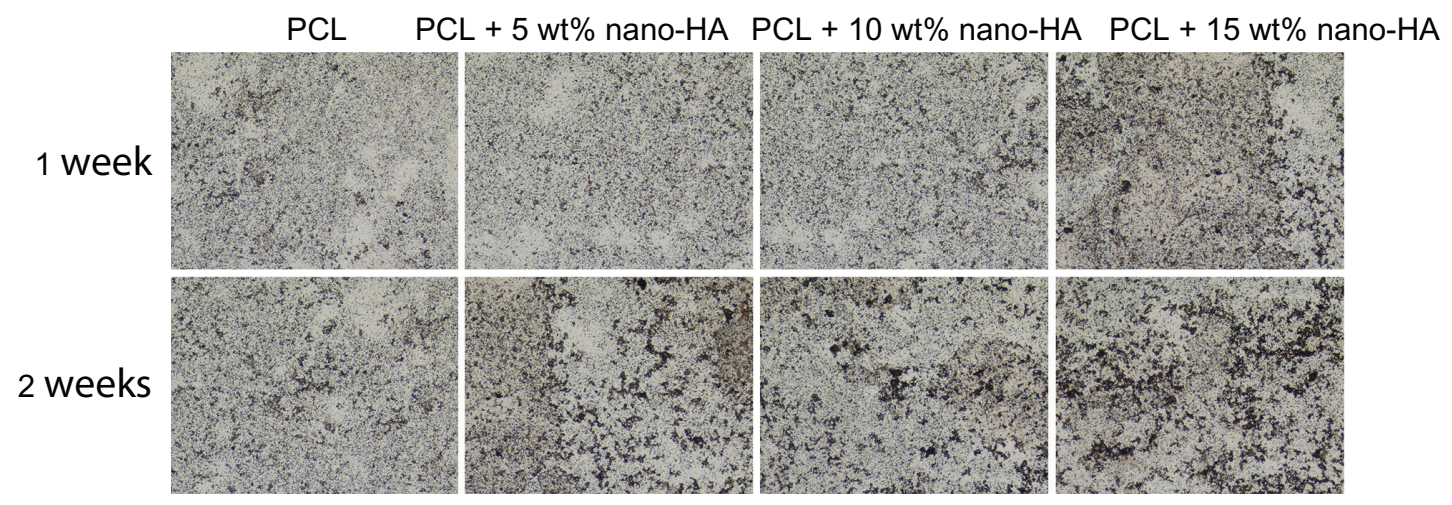

Figure 8 Alkaline phosphatase staining of human bone marrow stromal cells cultured on pure PCL and PCL with 5 wt\%, I0 wt\%, and I5 wt\% nano-HA scaffolds at I and 2 weeks in common medium.

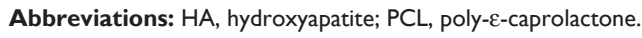




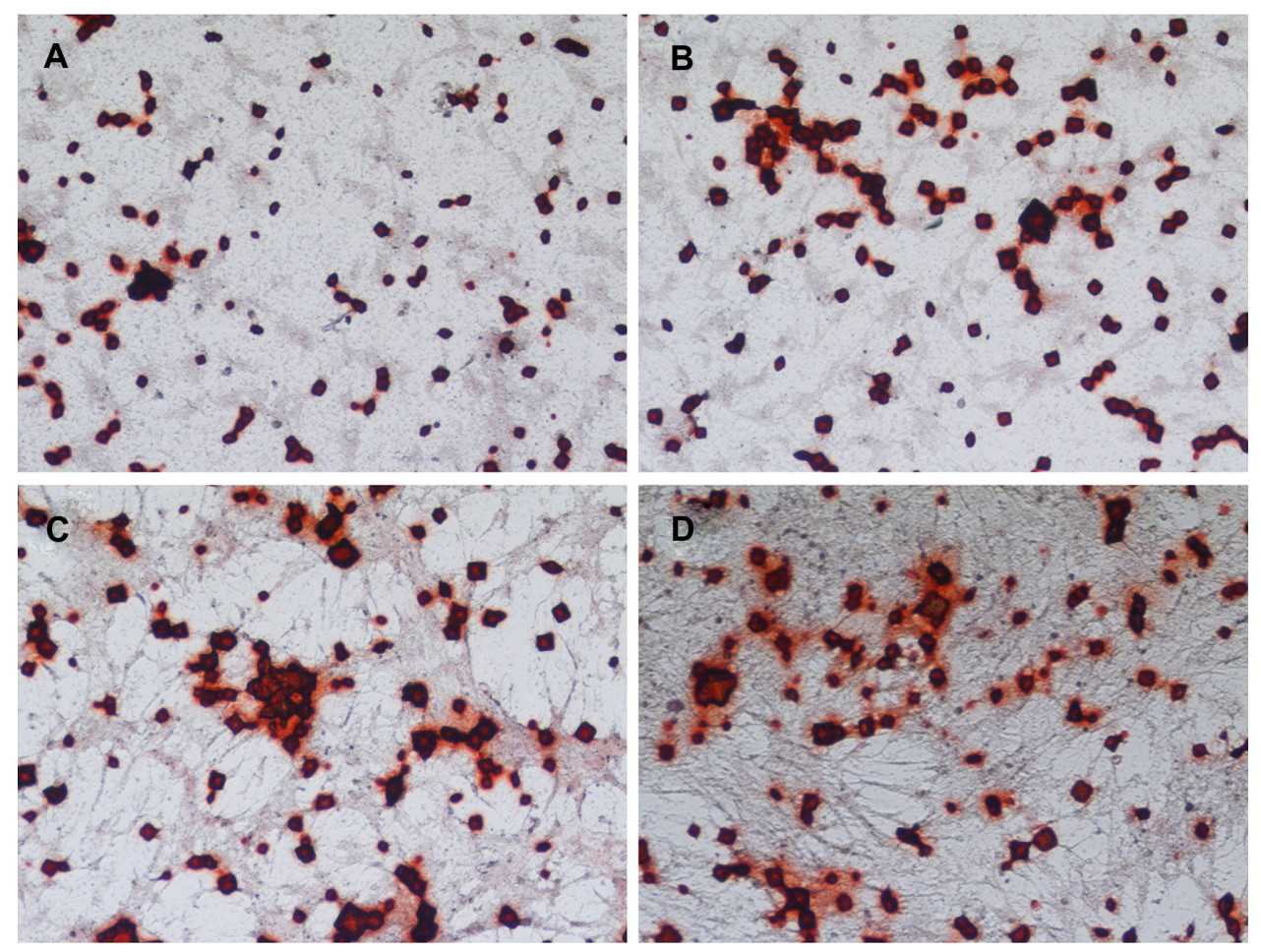

Figure 9 Alizarin Red S staining of human bone marrow stromal cells (hMSCs) on four groups of scaffolds.

Notes: hMSCs cultured on (A) pure poly- $\varepsilon$-caprolactone and poly- $\varepsilon$-caprolactone with (B) 5 wt\%, (C) 10 wt\%, and (D) 15 wt\% nano-hydroxyapatite scaffolds at 21 days in common medium.

In the PCL $+15 \%$ HA group, at 60 hours, 120 hours, 240 hours, and 360 hours, the percentages of rhBMP- 2 release were $42.3 \% \pm 3.57 \%, 53.1 \% \pm 2.83 \%, 67.9 \% \pm 2.76 \%$, and $73.8 \% \pm 2.47 \%$, respectively. Among the four groups of scaffolds, the PCL $+15 \%$ HA group showed the best release result.

Figure 11 illustrates the ALP expression in cells in the four groups after the scaffold adsorbed rhBMP-2 followed by co-culture with the hMSCs for 4, 7, and 14 days. As the culture time increased, ALP expression in each group gradually increased. On day 4, ALP expression in the four groups was basically the same. On day 7, however, ALP expression in the PCL $+15 \%$ HA group was significantly higher compared to the other four groups. On day 14, ALP expression in the control group and that in the pure PCL group were about the same, whereas ALP expressions in all groups that contained nano-HA scaffold cells were markedly higher compared to the control group. Among the three PCL + HA groups, the ALP expression in the PCL $+15 \%$ HA group was notably higher than in the other two groups.

\section{Biocompatibility and osteogenesis in vivo Postoperative general behavior of the rabbits}

Figure 12 shows the rabbit femur defect model and implantation. All the rabbits regained consciousness
1 hour post-surgery. Eating and other behaviors were reduced during the first day and returned to normal after 1 day, but no abnormal gait was observed. The wound showed no obvious infection.

\section{Radiography}

The rabbits were scanned in a micro-CT system at 3, 6, and 9 weeks for evaluation of in vivo osteogenesis of the nano-HA/ PCL scaffolds (Figure 13). The micro-CT images showed no bone formation within the muscles or outside the original drill hole at any point. At 3 weeks, the bone defect at the distal end of the femur was still obvious in the rabbits of all the groups. At 6 weeks, new bone formation was barely observable at the site of the bone defect in the blank control group. In the pure PCL group, newly formed bone tissue was seen in part of the bone defect, but no new cortical bone was found. In the group with PCL and $15 \mathrm{wt} \%$ nano-HA scaffolds, however, the bone defect was almost filled with newly formed bone tissue, and the surface of the newly formed bone cortex was irregular. The rabbits in the control group showed no significant difference between weeks 6 and 9; there was only a small amount of new bone tissue in the defect. The pure PCL scaffolds were associated with even less bone formation during the same period, although the radiopaque areas did grow over time and 


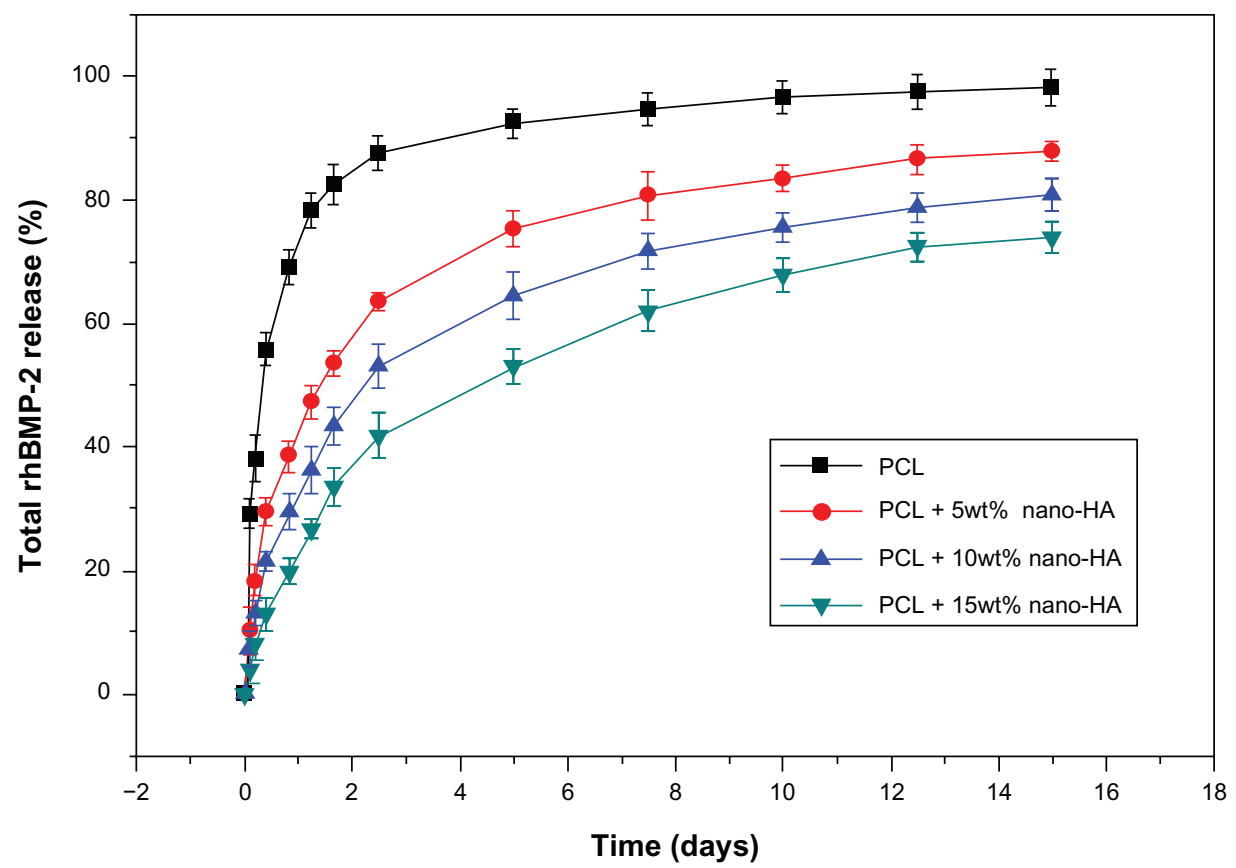

Figure 10 The cumulative in vitro release curves of the scaffolds over a period of 15 days.

Note: The plot was presented in terms of the percentage mass released over the original mass of protein.

Abbreviations: HA, hydroxyapatite; PCL, poly-e-caprolactone; rhBMP-2, recombinant human bone morphogenetic protein-2.

an umbilicated cavity formed in the bone cortex at 9 weeks. The PCL + $15 \mathrm{wt} \%$ nano-HA scaffold group showed the most extensive bone ingrowth throughout the entire volume of the implants, and thus nano-HA may play an important role in the formation of new bone cortex.

\section{Histological evaluation}

Histology was used to evaluate the formation of new bone tissue formation inside the macropores of the scaffolds in all groups. Cross-section photomicrographs were taken through the bone defect sites at 3 and 9 weeks and are shown

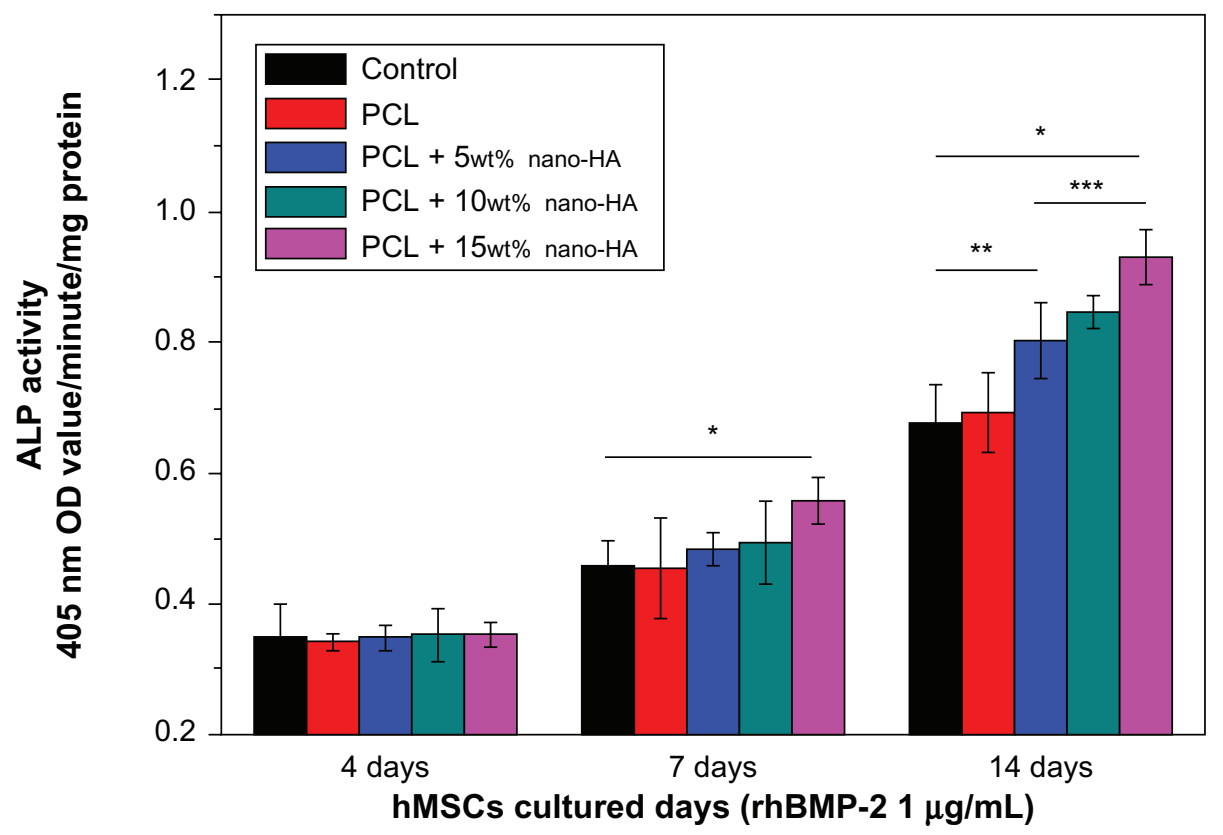

Figure I I ALP expression in different groups after loading the scaffolds with rhBMP-2 and then co-culturing with hMSCs for 4, 7, and I4 days ( $\mathrm{n}=5$ ).

Notes: $* P<0.05 \mathrm{PCL}+15 \mathrm{wt} \%$ nano-HA versus control; **P $<0.05 \mathrm{PCL}+5 \mathrm{wt} \%$ nano-HA versus control; $* * * P<0.05 \mathrm{PCL}+15 \mathrm{wt} \%$ nano-HA versus $\mathrm{PCL}+5 \mathrm{wt} \%$ nano-HA.

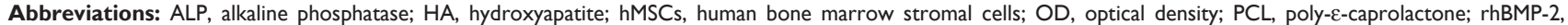
recombinant human bone morphogenetic protein-2. 

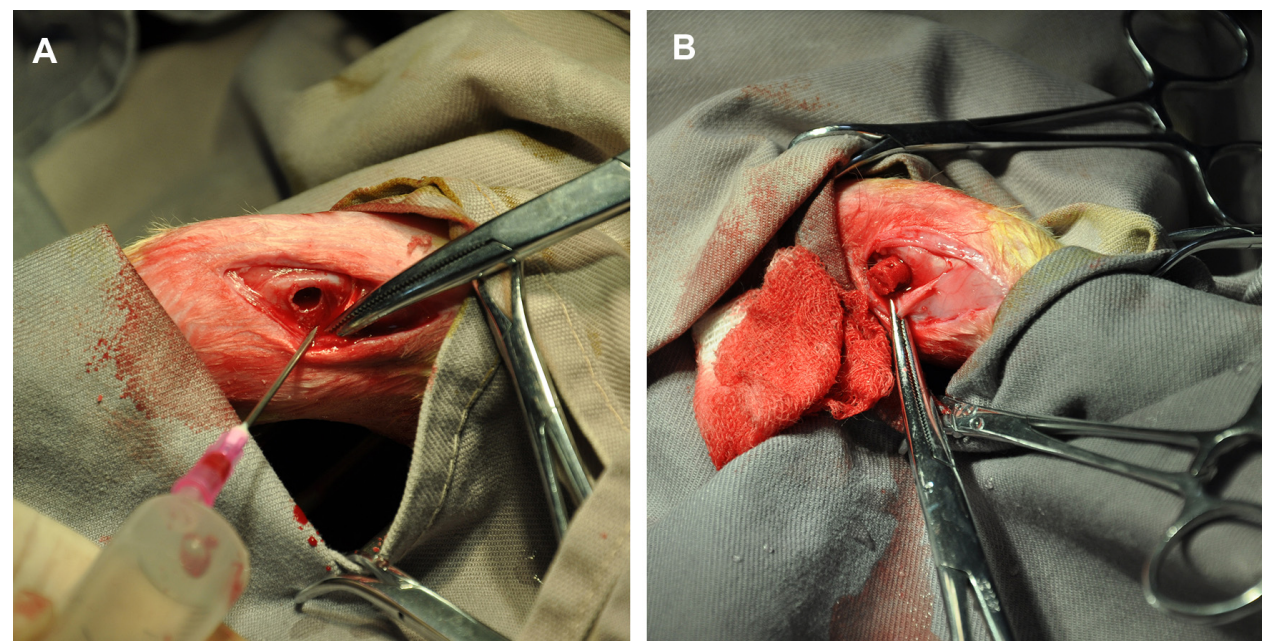

Figure 12 The rabbit femur defect model and implantation.

Notes: (A) A diameter of $5 \mathrm{~mm}$ and a depth of $10 \mathrm{~mm}$ defect was created by a $2 \mathrm{~mm}$ drill bit on the distal ends of the femurs. (B) The scaffolds (pure poly- $\varepsilon$-caprolactone and $15 \%$ nano-hydroxyapatite/poly- $\varepsilon$-caprolactone) were placed into the defects.

in Figure 14. At 3 weeks, both implant groups showed minimal resorption of materials, and new bone formation was observed around the materials in the vicinity of the bone marrow. The PCL + $15 \mathrm{wt} \%$ nano-HA group (Figure 14B-1 and B-2) showed a more extensive degradation than the pure PCL group (Figure 14A-1 and A-2), and the newly formed bone along the degrading material was trabecular with osteoid depositions at the surfaces of the material residuals. A large number of multinucleate giant cells were found in the pores of residual scaffolds and near the surfaces of the pore walls in both implant groups. These cells played an important role in scaffold degradation and osteogenesis similar to osteoclasts and osteoblasts. After 9 weeks, the PCL with $15 \mathrm{wt} \%$ nano-HA scaffolds (Figure 14D-1 and D-2) showed nearly complete degradation. The space previously filled with scaffold had been almost entirely replaced by fibrous tissue. However, in animals with pure PCL scaffolds (Figure 14C-1 and $\mathrm{C}-2$ ), the wound still contained a great deal of residual

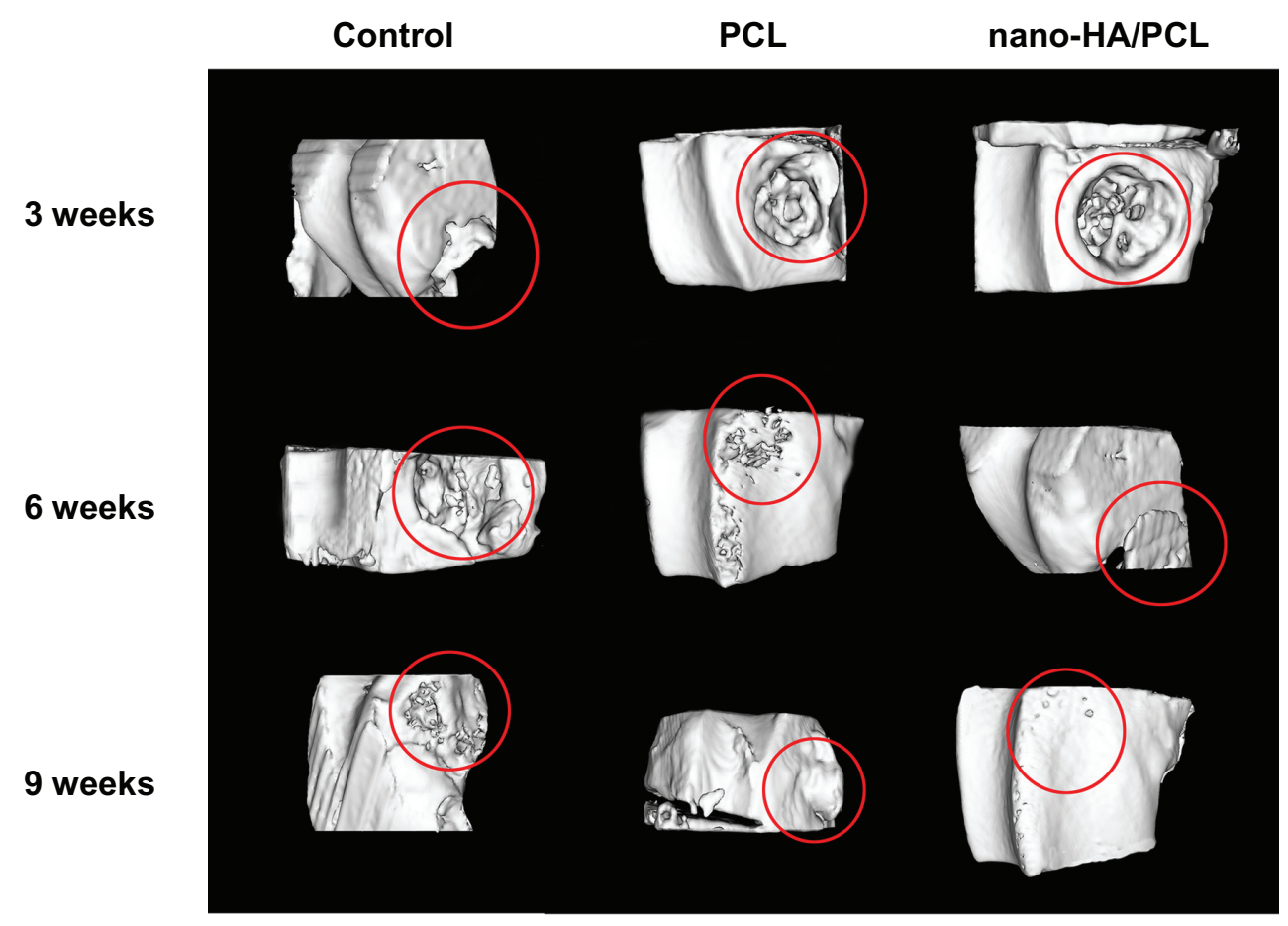

Figure 13 Tridimensional reconstruction of images by micro-computed tomography at 3, 6, and 9 weeks after production of a cavitary defect in the rabbit femur. Abbreviations: HA, hydroxyapatite; PCL, poly- $\varepsilon$-caprolactone. 

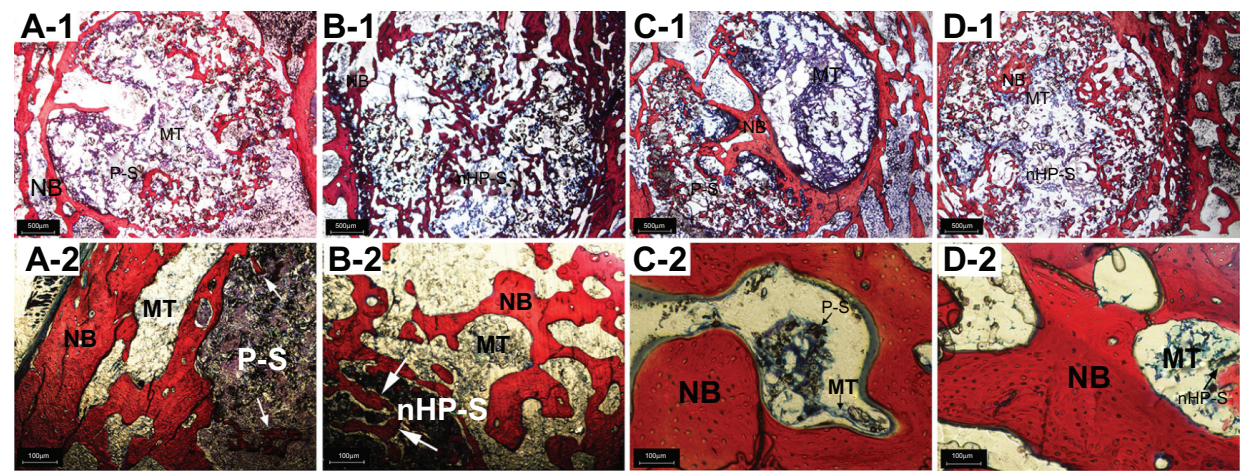

Figure 14 Histological evaluation of new bone formation promoted by pure PCL and I5\% nano-HA/PCL scaffolds (20× and I00× magnification).

Notes: Explanted bones were embedded in polymethylmethacrylate and processed for Van Gieson's staining. Bone defects with implantation of (A-I and A-2) pure PCL and (B-I and B-2) PCL with 15 wt\% nano-HA scaffolds at 3 weeks. Bone defects with implantation of (C-I and C-2) pure PCL and (D-I and D-2) PCL with I5 wt\% nano-HA scaffolds at 9 weeks. White arrows: newly formed bone along the degrading material.

Abbreviations: HA, hydroxyapatite; MT, bone marrow tissue; NB, new bone; nHP-S, PCL with I5 wt\% nano-HA scaffolds; PCL, poly-ع-caprolactone; P-S, pure PCL scaffolds.

material surrounded by fibrous tissue. Newly formed bone was the predominant feature in the repair area and woven bone was replaced by mature trabecular bone. New bone formation was more extensive in the nano-HA/PCL group than in the pure PCL group. This was consistent with the micro-CT analysis.

\section{Discussion}

In bone tissue engineering, 3D scaffolds provide an ideal structure for cell growth and tissue reconstruction. It is generally believed that scaffolds with over $70 \%$ porosity and pore diameters ranging from $100-900 \mu \mathrm{m}$ are highly favorable to cell infiltration, proliferation, osteogenic differentiation, and bone formation. ${ }^{29,30} \mathrm{HA}$ in natural bone tissue contains nanoscale, needle-like crystals, measuring $25-50 \mathrm{~nm}$ in length and well-arrayed in collagen fibers. Thus, we reasoned that adding nanoscale HA to the PCL powder to better simulate the structure and function of natural bone would improve the results of bone grafting. ${ }^{31,32}$ In the current study, we used SLS to successfully fabricate nano-HA/PCL scaffolds with $70 \%-75 \%$ porosity, well-ordered macropores, and irregular micropores. The interconnected macropores and micropores facilitated blood vessel migration, cellular nutrient diffusion, and waste exchange.

Bone tissue scaffolds need to have superior mechanical properties. In this study, the amount of inorganic constituents in the scaffold was associated with lower porosity and higher compressive strength. This indicates a close relationship between the porosity and mechanical properties and the ratio of organic to inorganic constituents in the material. Bone can be considered a nano-composite of collagen protein fibers and a HA mineral phase that makes up about $77 \%$ of the bone structure by weight. In this study, different proportions of the nano-HA to PCL were used in the scaffold to determine which material could best simulate the mechanical strength of natural bone.

The results showed that the scaffolds made of PCL with $15 \mathrm{wt} \%$ nano-HA demonstrated the best mechanical properties. The most suitable ratio of nano-HA weight to PCL weight was 15:85, producing a scaffold with a compressive strength of $3.1724 \pm 0.1109 \mathrm{MPa}$. Scaffolds with this proportion of nano-HA to PCL were used in an in vivo experiment; however, these scaffolds did not show as much compressive strength as natural cortical bone $(80-150 \mathrm{MPa}){ }^{33}$ This might be because they were highly porous or because of the poor mechanical properties of the PCL itself, which were only somewhat mitigated by reinforcement with nano-HA. We therefore recommend that this type of fabricated scaffold be used only in non-load-bearing areas.

In this study, in vitro experiments focusing on the biocompatibility and bioactivity of nano-HA/PCL scaffolds were performed. MSCs were loaded onto porous scaffolds and may constitute a suitable approach to the reconstruction of bone defects. ${ }^{34,35}$ Cell attachment, toxicity, and proliferation experiments showed that the biocompatibility of nano-HA/PCL scaffolds was as good as that of pure PCL scaffolds. The results of the hydrophilicity experiments, SBF immersion, ALP assay, and Alizarin Red S staining showed that the bioactivity of nano-HA/PCL scaffolds is superior to that of pure PCL scaffolds. This was attributed to the pronounced effect of nano-HA on the proliferation of HMSCs, differentiation of osteoblasts, and mineralization of bone. Strong chemical bonds can be formed between HA and the bone interface, showing good osteoconduction after implantation of HA into areas of bone defect. HA can also 
mimic the structure and function of the extracellular matrix to support expanded cells.

Previous studies have demonstrated that scaffolds made of osteoconductive bioceramics and bioresorbable materials allow bone cell growth into the scaffold centers. ${ }^{36}$ However, scaffolds made of biodegradable materials alone allow newly formed bone matrix growth only at their surfaces. ${ }^{37}$ Causa et $\mathrm{al}^{38}$ further confirmed the effects of HA on osteoconduction and on the proliferation and differentiation of osteoblasts when the scaffolds were made of HA and high-molecular-weight polymer mixtures. Again, the HA could increase the mechanical strength of the scaffolds. ${ }^{35-37}$ Wang et $\mathrm{al}^{39}$ and Hayati et $\mathrm{al}^{40}$ also found that HA can increase the mechanical properties of polymer-based composites, all consistent with our findings.

HA is an important biological material, and its application in adsorbing biologically active macromolecules such as proteins has been expanding. Miyaji et $\mathrm{al}^{41}$ reported the application of HA in blood purification due to its selective adsorption. Fujii et $\mathrm{al}^{42}$ proposed that HA could be used to isolate viral proteins. In these studies, it was generally believed that the complex surface crystal structure of HA and the electrostatic interactions between the adsorbed substances and the HA crystal surface are the main basis for selective adsorption. HA belongs to the hexagonal crystal system. Its structure is a hexagonal prism, with a unit cell of $10 \mathrm{Ca}^{2+}$, six $\mathrm{PO}_{4}{ }^{3-}$, and two $\mathrm{OH}^{-}$. The $\mathrm{Ca}^{2}$ on its surface can bind with the negatively charged BMP-2 via electrostatic interactions. Hence HA has a strong capacity to absorb BMP-2. Studies by Fu et $\mathrm{al}^{43}$ and Jeon et $\mathrm{al}^{44}$ also showed that, after addition of $\mathrm{HA}$, the ability of the material to facilitate sustained release of BMP-2 was significantly improved. This is consistent with our BMP-2 data.

The results of the in vitro experiments facilitated the design of our subsequent in vivo experiments, in which we confirmed the biocompatibility and bone repair function of the nano-HA/PCL scaffolds. All rabbits showed good healing at the surgical site and remained healthy. This showed that the nano-HA/PCL scaffolds are as biocompatible as pure PCL scaffolds. This was consistent with the results of our in vitro experiments. To monitor the formation of bone tissue, micro-CT images and histological studies were performed on the specimens after different periods of implantation.

Active bone regeneration was found in the defects of the pure PCL scaffold and nano-HA/PCL construct groups. However, nano-HA/PCL constructs presented faster and more effective osteogenesis at the defect area than pure PCL scaffolds across various implantation periods. The control group showed the slowest bone growth. These results indicate that the nano-HA in the composite scaffolds could promote osteogenesis in vivo. These results and the in vitro data show that the role of nano-HA in the promotion of bone formation in vivo might be due to its ability to enhance surface properties, including increasing the surface area with charge effects to attract chemical species. This promotes hMSC responsiveness, proliferation, and osteogenic differentiation, thereby promoting bone mineralization. ${ }^{45}$

\section{Conclusion}

In the present study, pure PCL and nano-HA/PCL composite scaffolds were successfully fabricated using a SLS technique. The results demonstrate that the pure PCL and nano-HA/PCL composite scaffolds ranged in porosity from $78.54 \%$ to $70.31 \%$ and in compressive strength from $1.38 \mathrm{MPa}$ to 3.17 MPa. The scaffolds showed well-ordered macropores and interconnected micropores, which favored cell seeding and spatial distribution of transplanted cells. The in vitro experiments showed that the hMSCs grown on the nano-HA/PCL composite scaffolds exhibited a higher degree of attachment, growth, and osteogenic differentiation than those grown on pure PCL scaffolds. The in vivo experiments demonstrated that both implanted pure PCL scaffolds and nano-HA/PCL scaffolds were reasonably biocompatible. The nano-HA/PCL constructs presented faster and more effective osteogenesis than pure PCL scaffolds.

\section{Acknowledgment}

We acknowledge the support of the Nano Project of Science and Technology Commission of Shanghai Municipality (No 1052nm03100), Key Projects for Basic Research Shanghai Committee of Science and Technology (No 11JC1415700), and the National Natural Science Foundation of China (No 81171794).

\section{Disclosure}

The authors report no conflicts of interest in this work.

\section{References}

1. Frohbergh ME, Katsman A, Botta GP, et al. Electrospun hydroxyapatitecontaining chitosan nanofibers crosslinked with genipin for bone tissue engineering. Biomaterials. 2012;33(36):9167-9178.

2. Wang X, Ma J, Wang Y, He B. Bone repair in radii and tibias of rabbits with phosphorylated chitosan reinforced calcium phosphate cements. Biomaterials. 2002;23(21):4167-4176.

3. Yuan HP, Fernandes H, Habibovic P, et al. Osteoinductive ceramics as a synthetic alternative to autologous bone grafting. Proc Natl Acad Sci U $S$ A. 2010;107(31):13614-13619.

4. De Long WG Jr, Einhorn TA, Koval K, et al. Bone grafts and bone graft substitutes in orthopedic trauma surgery: a critical analysis. J Bone Joint Surg Am. 2007;89(3):649-658. 
5. Seunarine K, Gadegaard N, Tormen M, Meredith DO, Riehle MO, Wilkinson CD. 3D polymer scaffolds for tissue engineering. Nanomedicine (Lond). 2006;1(3):281-296.

6. O'Brien FJ. Biomaterials and scaffolds for tissue engineering. Materials Today. 2011;14(3):88-95.

7. Hollister SJ. Porous scaffold design for tissue engineering. Nat Mater. 2005;4(7):518-524

8. Thomson RC, Yaszemski MJ, Powers JM, Mikos AG. Hydroxyapatite fiber reinforced poly $(\alpha$-hydroxy ester) foams for bone regeneration. Biomaterials. 1998;19(21):1935-1943.

9. Taboas JM, Maddox RD, Krebsbach PH, Hollister SJ. Indirect solid free form fabrication of local and global porous, biomimetic and composite 3D polymer-ceramic scaffolds. Biomaterials. 2003;24(1):181-194.

10. Ji CD, Khademhosseini A, Dehghani F. Enhancing cell penetration and proliferation in chitosan hydrogels for tissue engineering applications. Biomaterials. 2011;32(36):9719-9729.

11. Xianmiao C, Yubao L, Yi Z, Li Z, Jidong L, Huanan W. Properties and in vitro biological evaluation of nano-hydroxyapatite/chitosan membranes for bone guided regeneration. Mater Sci Eng C Mater Biol Appl. 2009;29(1):29-35.

12. Melchels FP, Bertoldi K, Gabbrielli R, Velders AH, Feijen J, Grijpma DW. Mathematically defined tissue engineering scaffold architectures prepared by stereolithography. Biomaterials. 2010;31(27):6909-6916.

13. Hutmacher DW, Sittinger M, Risbud MV. Scaffold-based tissue engineering: rationale for computer-aided design and solid free-form fabrication systems. Trends Biotechnol. 2004;22(7):354-362.

14. Ryan G, Pandit A, Apatsidis DP. Fabrication methods of porous metals for use in orthopaedic applications. Biomaterials. 2006;27(13):2651-2670.

15. Lopez-Heredia MA, Sohier J, Gaillard C, Quillard S, Dorget M, Layrolle P. Rapid prototyped porous titanium coated with calcium phosphate as a scaffold for bone tissue engineering. Biomaterials. 2008;29(17):2608-2615.

16. Williams JM, Adewunmi A, Schek RM, et al. Bone tissue engineering using polycaprolactone scaffolds fabricated via selective laser sintering. Biomaterials. 2005;26(23):4817-4827.

17. Duan B, Wang M,ZhouWY,Cheung WL, LiZY,LuWW.Three-dimensional nanocomposite scaffolds fabricated via selective laser sintering for bone tissue engineering. Acta Biomater. 2010;6(12): 4495-4505.

18. Wiria FE, Leong KF, Chua CK, Liu Y. Poly-epsilon-caprolactone/ hydroxyapatite for tissue engineering scaffold fabrication via selective laser sintering. Acta Biomater. 2007;3(1):1-12.

19. Eosoly S, Brabazon D, Lohfeld S, Looney L. Selective laser sintering of hydroxyapatite/poly-e-caprolactone scaffolds. Acta Biomater. 2010;6(7):2511-2517.

20. Thein-Han WW, Shah J, Misra RDK. Superior in vitro biological response and mechanical properties of an implantable nanostructured biomaterial: Nanohydroxyapatite-silicone rubber composite. Acta Biomater. 2009;5(7):2668-2679.

21. Khang D, Choi J, Im YM, et al. Role of subnano-, nano- and submicron-surface features on osteoblast differentiation of bone marrow mesenchymal stem cells. Biomaterials. 2012;33(26):5997-6007.

22. Xu CX, Su PQ, Chen XF, et al. Biocompatibility and osteogenesis of biomimetic bioglass-collagen-phosphatidylserine composite scaffolds for bone tissue engineering. Biomaterials. 2011;32(4):1051-1058.

23. ASTM International. ASTM D695-10. Standard Test Method For Compressive Properties of Rigid Plastics. West Conshohocken, PA: ASTM International; 2002.

24. Peng ZX, Wang L, Du L, Guo SR, Wang XQ, Tang TT. Adjustment of the antibacterial activity and biocompatibility of hydroxypropyltrimethyl ammonium chloride chitosan by varying the degree of substitution of quaternary ammonium. Carbohydr Polym. 2010;81(2):275-283.

25. Lowry OH, Roberts NR, Wu M, Hixton WS, Crawford EJ. The quantitative histochemistry of brain. II. Enzyme measurements. J Biol Chem. 1954;207(1):19-37.

26. Lieberherr M, Vreven J, Vaes G. The acid and alkaline phosphatases, inorganic pyrophosphatases and phosphoprotein phosphatase of bone. I. Characterization and assay. Biochim Biophys Acta. 1973;293(1): $160-169$.
27. Kokubo T, Kushitani H, Kitsugi S, Yammamuro T. Solutions able to reproduce in vivo surface-structure changes in bioactive glass-ceramic A-W. J Biomed Mater Res. 1990;24(6):721-734.

28. Yu S, Hariram KP, Kumar R, Cheang P, Aik KK. In vitro apatite formation and its growth kinetics on hydroxyapatite/polyetheretherketone biocomposites. Biomaterials. 2005;26(15):2343-2352.

29. de Real RP, Wolke JG, Vallet- Regí M, Jansen JA. A new method to produce macropores in calcium phosphate cements. Biomaterials. 2002;23(17):3673-3680.

30. Ma PX. Scaffolds for tissue fabrication. Materials Today. 2004;7(5): $30-40$.

31. Poinern GE, Brundavanam RK, Mondinos N, Jiang ZT. Synthesis and characterisation of nanohydroxyapatite using an ultrasound assisted method. Ultrason Sonochem. 2009;16(4):469-474.

32. Hellmich C, Ulm FJ. Average hydroxyapatite concentration is uniform in the extracollagenous ultrastructure of mineralized tissues: evidence at the 1-10-microm scale. Biomech Model Mechanobiol. 2003;2(1): 21-36.

33. Anseth KS, Shastri VR, Langer R. Photopolymerizable degradable polyanhydrides with osteocompatibility. Nat Biotechnol. 1999;17(2): 156-159.

34. Wang YW, Wu Q, Chen GQ. Attachment, proliferation and differentiation of osteoblasts on random biopolyester poly(3hydroxybutyrate-co-3-hydroxyhexanoate) scaffolds. Biomaterials. 2004;25(4):669-675.

35. Xin X, Hussain M, Mao JJ. Continuing differentiation of human mesenchymal stem cells and induced chondrogenic and osteogenic lineages in electrospun PLGA nanofiber scaffold. Biomaterials. 2007;28(2): 316-325.

36. Ma PX, Zhang R, Xiao G, Franceschi R. Engineering new bone tissue in vitro on highly porous poly(alpha-hydroxyl acids)/ hydroxyapatite composite scaffolds. J Biomed Mater Res. 2001;54(2): 284-293

37. Ishaug SL, Crane GM, Miller MJ, Yasko AW, Yaszemski MJ, Mikos AG. Bone formation by three-dimensional stromal osteoblast culture in biodegradable polymer scaffolds. J Biomed Mater Res. 1997;36(1): $17-28$.

38. Causa F, Netti PA, Ambrosio L, et al. Poly-epsilon-caprolactone/ hydroxyapatite composites for bone regeneration: in vitro characterization and human osteoblast response. J Biomed Mater Res A. 2006;76(1): $151-162$.

39. Wang HN, Li Yb, Zuo Y, Li JH, Ma SS, Cheng L. Biocompatibility and osteogenesis of biomimetic nano-hydroxyapatite/polyamide composite scaffolds for bone tissue engineering. Biomaterials. 2007;28(22): $3338-3348$

40. Hayati AN, Hosseinalipour SM, Rezaie HR, Shokrgozar MA. Characterization of poly(3-hydroxybutyrate)/nano-hydroxyapatite composite scaffolds fabricated without the use of organic solvents for bone tissue engineering applications. Mater Sci Eng C Mater Biol Appl. 2012;32(3):416-422.

41. Miyaji F, Kono Y, Suyama Y. Formation and structure of zinc-substituted calcium hydroxyapatite. Mater Res Bull. 2005;40(2):209-220.

42. Fujii E, Ohkubo M, Tsuru K, et al. Selective protein adsorption property and characterization of nano-crystalline zinc-containing hydroxyapatite. Acta Biomater. 2006;2(1):69-74

43. Fu YC, Nie H, Ho ML, Wang CK, Wang CH. Optimized bone regeneration based on sustained release from three-dimensional fibrous PLGA/ HAp composite scaffolds loaded with BMP-2. Biotechnol Bioeng. 2008;99(4):996-1006.

44. Jeon BJ, Jeong SY, Koo AN, Kim BC, Hwang YS, Lee SC. Fabrication of porous PLGA microspheres with BMP-2 releasing polyphosphatefunctionalized nano-hydroxyapatite for enhanced bone regeneration. Macromolecular Research. 2012;20(7):715-724.

45. Venugopal J, Prabhakaran MP, Zhang YZ, Low S, Choon AT, Ramakrishna S. Biomimetic hydroxyapatite-containing composite nanofibrous substrates for bone tissue engineering. Philos Trans A Math Phys Eng Sci. 2010;368(1917):2065-2081. 


\section{Supplementary material}

$\mathrm{HaCaT}$ cells were co-cultured with the scaffold for 7 days, and then fixed. A cross-section of the scaffold was sampled, and scanning electronic microscopy showed that,
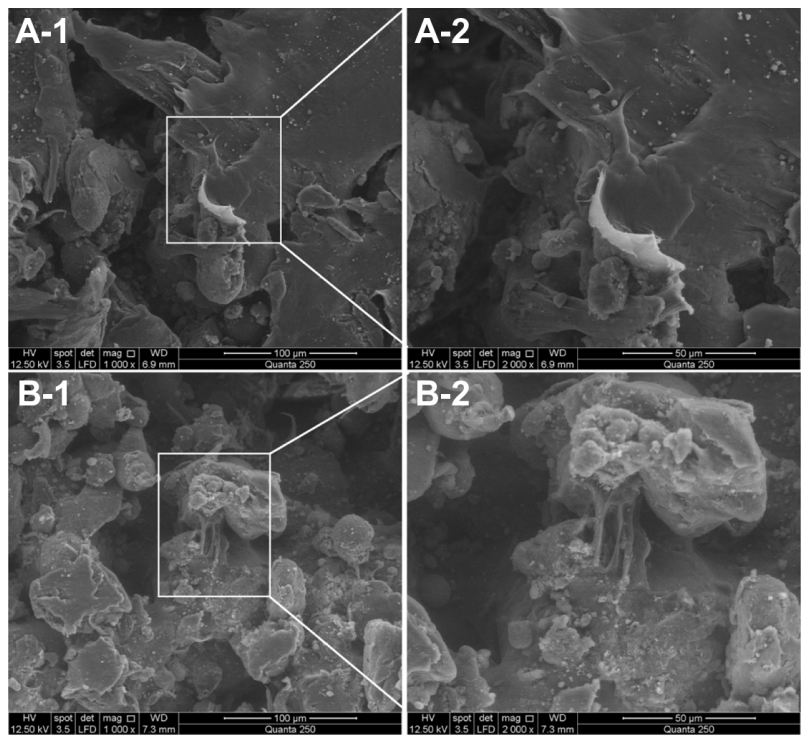

Figure SI Scanning electronic microscopy of the cross-section of the scaffold after the $\mathrm{HaCaT}$ cells were co-cultured with the scaffold for 7 days.

Notes: $($ A-I and B-I $) \times 200$; $($ A-2 and B-2) $\times 400$. after 7 days, HaCaT cells had grown into the scaffold (Figure S1).
International Journal of Nanomedicine

\section{Publish your work in this journal}

The International Journal of Nanomedicine is an international, peerreviewed journal focusing on the application of nanotechnology in diagnostics, therapeutics, and drug delivery systems throughou the biomedical field. This journal is indexed on PubMed Central, MedLine, CAS, SciSearch $\AA$, Current Contents ${ }^{\circledR} /$ Clinical Medicine,
Dovepress

Journal Citation Reports/Science Edition, EMBase, Scopus and the Elsevier Bibliographic databases. The manuscript management system is completely online and includes a very quick and fair peer-review system, which is all easy to use. Visit http://www.dovepress.com/ testimonials.php to read real quotes from published authors. 